\title{
Entre a simplificação e a complexidade, a heterogeneidade: Teoria Ator-Rede e uma nova epistemologia para os estudos organizacionais
}

\author{
VERÔNICA MACÁRIO de OLIVEIRA \\ UnidAde Federal de CAMpINA GRANDE (UFCG) / UnIDADE ACADÊMICA DE AdMINISTRAÇÃo E CONTABILIDADE (UAAC), CAMPINA GRANDE - PB, BRASIL \\ JosÉ de ARIMATÉIA DIAS VALADÃo \\ UNIVERSIDADE FEDERAL de LAVRAS (UFLA) / DEPARTAMENTO dE AdMINISTRAÇÃo E ECONOMIA (DAE/UFLA), LAVRAS - MG, BRASIL
}

\begin{abstract}
Resumo
Este artigo discute e reflete sobre a relevância de considerar a mediação foco de análise da heterogeneidade na Teoria Ator-Rede (TAR) nos estudos organizacionais, confrontando-a com duas perspectivas paradigmáticas muito discutidas atualmente-simplificação e complexidade. Para tanto, inicialmente, trata da crise do paradigma moderno, mostra a transição desse paradigma para o paradigma da complexidade e situa os estudos organizacionais nesse novo paradigma. Em seguida, mostra sinteticamente a trajetória histórica da heterogeneidade e então evidencia como ela é conceituada na TAR como possibilidade epistemológica para os estudos organizacionais. Por fim, destaca algumas considerações sobre a mediação como foco de análise da heterogeneidade na TAR. O argumento defendido é que, a partir da análise heterogênea dos fatores sociais, tecnológicos e naturais, inter-relacionados no que a TAR denomina atores-redes, é possível superar, nos estudos organizacionais, a circularidade em que os paradigmas modernos da simplificação e da complexidade estão inseridos. Isso porque a heterogeneidade, da forma como pressuposta no contexto da simplificação ou complexidade, trata-se, sobretudo, de concepções estáticas da realidade e, para a TAR, a heterogeneidade é sobretudo relacional, trata-se de fluxos dos coletivos e das maneiras como eles se comportam, estejam eles se apresentando simples, complexos, ordenados ou fluidos. A partir dessas reflexões, este artigo sugere que se basear, epistemologicamente, nos pressupostos da heterogeneidade da TAR constitui uma lente de análise relevante para compreensão dos fenômenos organizacionais.
\end{abstract}

Palavras-chave: Epistemologia. Paradigma. Complexidade. Heterogeneidade. Teoria do Ator-Rede.

Heterogeneity between simplification and complexity: Actor-Network Theory and a new epistemology for organizational studies

\begin{abstract}
This article discusses and reflects on the relevance of considering mediation as focus of analysis of heterogeneity in the Actor Network Theory (ANT) when it comes to organizational studies, comparing it with two paradigmatic perspectives much discussed today- simplification and complexity. Therefore, it initially deals with the modern paradigm crisis, showing the transition of this paradigm to the paradigm of complexity and places organizational studies in this new paradigm. Then, the study synthetically shows the historical path of heterogeneity, and then shows how this is conceptualized in ANT as an epistemological possibility to organizational studies. Finally, it highlights some considerations about mediation as focus of analysis of heterogeneity in ANT. The main argument is that from the heterogeneous analysis of the social, natural and technological factors interrelated in what ANT calls "actors networks", it is possible to overcome, in organizational studies, the circularity in which the modern paradigms of simplification and complexity are inserted. This is because the heterogeneity, the way proposed in the context of simplification and complexity, consists mainly of static conceptions of reality and ANT, heterogeneity is primarily relational, it is the flow of collectives and the ways they behave, whether they are performing simple, complex, ordered or fluid activities. From these reflections, the article is based, epistemologically, on the heterogeneity assumptions of ANT as a lens of analysis relevant to understanding the organizational phenomena.
\end{abstract}

Keywords: Epistemology. Paradigm. Complexity. Heterogeneity. Actor-Network Theory.

\section{Entre la simplificación y la complejidad, la heterogeneidad: Teoría del Actor-Red y una nueva epistemología para los estudios organizacionales}

\begin{abstract}
Resumen
Este artículo discute y reflexiona sobre la relevancia de considerar la mediación como foco de análisis de la heterogeneidad en la Teoría del Actor-Red (TAR), en los estudios organizacionales, confrontándola con dos perspectivas paradigmáticas muy discutidas actualmente -simplificación y complejidad-. Para ello, inicialmente, trata la crisis del paradigma moderno, muestra la transición de ese paradigma al paradigma de la complejidad y sitúa los estudios organizacionales en ese nuevo paradigma. Posteriormente, muestra sintéticamente la trayectoria histórica de la heterogeneidad y, entonces, evidencia cómo esta se conceptúa en la TAR como posibilidad epistemológica para los estudios organizacionales. Finalmente, destaca algunas consideraciones sobre la mediación como foco de análisis de la heterogeneidad en la TAR. El argumento que se defiende es que a partir del análisis heterogéneo de los factores sociales, tecnológicos y naturales interrelacionados, en el que la TAR denomina actores-redes, es posible superar, en los estudios organizacionales, la circularidad en que los paradigmas modernos de la simplificación y de la complejidad están insertados. Debido a que la heterogeneidad, de la forma como se presupone en el contexto de la simplificación o de la complejidad, se trata, sobre todo, de concepciones estáticas de la realidad y, para la TAR, la heterogeneidad es principalmente relacional, se trata de flujos de colectivos y de las maneras como estos se comportan, independientemente de que se presenten simples, complejos, ordenados o fluidos. A partir de esas reflexiones, este artículo sugiere que basarse epistemológicamente en los presupuestos de la heterogeneidad de la TAR constituye un lente de análisis relevante para la comprensión de los fenómenos organizacionales.
\end{abstract}

Palabras clave: Epistemología. Paradigma. Complejidad. Heterogeneidad. Teoría del Actor-Red. 


\section{INTRODUÇÃO}

Tradicionalmente, os estudos organizacionais foram fundamentados em princípios deterministas, simplificadores e reducionistas dos fenômenos investigados (BURREL, 2010; MORGAN, 1980, 2005; MARSDEN e TOWNLEY, 1999; BERTERO, 1999). Entretanto, há muito vem sendo dito que as ciências sociais não podem estabelecer leis universais porque os fenômenos sociais são historicamente condicionados e culturalmente determinados (SANTOS, 2000; WINNER, 1986). O que tem resultado em novos paradigmas emergentes (SANTOS, 2000; PLASTINO, 2001).

Essa mudança tem-se dado porque os objetos de investigação das ciências sociais têm fronteiras pouco definidas (GODOI, BANDEIRA-DE-MELO e SILVA, 2010). As organizações, por exemplo, constituem conjuntos de componentes interligados e conectados, cuja atuação ocorre mediante as interações estabelecidas entre diferentes atores e seus objetivos (LATOUR, 2000). Nesse fato se baseia uma das principais críticas à utilização das abordagens reducionistas nos estudos organizacionais, por ser acusada de não considerar a complexidade das organizações, o que as torna inadequadas para estudar a multidimensionalidade dos fenômenos investigados.

Em consequência, têm surgido várias abordagens interdisciplinares (SERVA, DIAS e ALPERSREDT, 2010) e transdisciplinares (GODOI, BANDEIRA-DE-MELO e SILVA, 2010) para lidar com esse problema. Uma dessas formas é a discussão sobre a emergência de um novo paradigma que considera a complexidade e a dinâmica da influência do ambiente no qual as organizações estão inseridas, bem como de sua interação com as outras organizações e seus diversos atores. Nessa perspectiva, para compreender a complexidade organizacional, têm-se enfatizado sua perspectiva histórica e evolutiva, principalmente com base em um enfoque sistêmico com o propósito de assegurar a possibilidade de lidar com as complexidades existentes e entender como o todo e as partes de um sistema se inter-relacionam (MORIN, 2000).

O chamado paradigma da complexidade (MORIN, 2000) tem argumentado sobre a possibilidade de estabelecer as relações e interdependências de todos os aspectos dos fenômenos sociais e da integração dos diferentes modos de pensar inerentes ao mundo social. Alega para si a tarefa de reconhecer os traços singulares, originais e históricos dos entes estudados, em vez de ligá-los pura e simplesmente a determinações ou leis gerais.

Entretanto, esse paradigma tem sido acusado de determinar o modus operandi da ciência a partir de uma teoria metacientífica, inexequível experimentalmente (ANDRADE, 2007). Além disso, a utilização de termos como autopoiese e outros próprios desse paradigma parece não trazer indicações de como efetivamente as mudanças ocorrem nas organizações. Do mesmo modo, a natureza do conhecimento científico parece sempre se apresentar insuficiente, precária e imprecisa em face do real e, em consequência, a transdisciplinaridade pretendida pelos pesquisadores esbarra nos contextos próprios de cada espaço científico e limita o entendimento do todo complexo e integrado que se argumenta encontrar nesse paradigma (SERVA, 1992).

Tem-se, assim, constituído um problema de natureza ontológica e que remete ao questionamento sobre o que de fato são as organizações. Esse problema dificulta, em decorrência, os esforços epistemológicos de conhecê-las. Da mesma forma que o paradigma da fragmentação e simplificação foi rotulado como negligente em termos de conhecimento genuíno, a unificação e combinação de diferentes campos teóricos, encaixados em um paradigma da complexidade, também parecem torná-lo inalcançável. Se o fundamento da realidade é uma constituição de partes simples, como afirmava Descartes, ou complexa, como alega Morin (ANDRADE, 2007), na prática da pesquisa científica parece haver barreiras intransponíveis que dificultam a circulação do pesquisador em ambientes naturais de pesquisa - como são as organizações.

Enquanto o paradigma moderno se prende demais ao passado, tentando compreender as estruturas ou a capacidade de agência humana nas transformações da realidade, o paradigma da complexidade se baseia excessivamente nas incertezas do futuro, além de pressupor ser possível, via um modelo teórico complexo, explicar a priori como a realidade se comporta e o que é preciso epistemologicamente para descrevê-la. Enquanto isso, o presente parece ficar marginalizado diante desses dois extremos.

Contudo, quando não mais é possível elaborar uma explicação científica para os fenômenos, os dois extremos paradigmáticos têm recorrido à mesma retórica. De que os objetos de pesquisa investigados são redes de relações embutidas em redes maiores e a partir de relações que escapam aos domínios científicos. Dessa forma, há uma negligência ao universo material e humano, visto como uma teia dinâmica de eventos inter-relacionados, que exercem e recebem influência associativa e interativamente. 
Abordagens mais recentes, como a Teoria Ator-Rede (TAR) (CALLON, 1986, 1998, 1999; LATOUR, 1988, 1992, 1994a, 1998, 1999, 2000, 2001, 2004, 2008, 2012; LAW, 1986, 1992, 1998, 1999, 2004, 2007, 2011) tem sido vista como uma alternativa viável para a compreensão desses aspectos, principalmente aos organizacionais e de suas mudanças (ALCADIPANI e TURETA, 2009; ANDRADE, 2004, 2010). Essa abordagem faz uma crítica ao posicionamento das abordagens tradicionais por se limitar a estudar as caixas-pretas já formadas ao longo do tempo e que, em consequência, pouco descrever o que de fato são as organizações. Bem como não pressupor uma incapacidade de descrição dos fenômenos em função de uma possível dinamicidade complexa inalcançável aos padrões científicos. Para a TAR, há um caminho do meio, heterogêneo e fluido, onde tudo flui e acontece.

Contudo, por que é possível atribuir à TAR uma responsabilidade que até então tem sido criticada nessas abordagens? Dizendo de outra maneira, por que é possível afirmar que a TAR possibilita avançar nessas limitações apresentadas e como ela lida com essa "teia de eventos inter-relacionados" que têm desafiado as comunidades científicas, principalmente aquelas debruçadas sobre os fenômenos mais diretamente relacionados às organizações?

Essa é a problemática em que esse artigo se insere. $O$ argumento apresentado é que a partir da análise heterogênea dos fatores sociais, tecnológicos e naturais, inter-relacionados no que a TAR denomina atores-redes, é possível superar a circularidade em que os paradigmas modernos da simplificação e da complexidade estão inseridos. Para tanto, o artigo está dividido, além desta introdução e da conclusão, em 7 seções. A segunda seção trata da crise do paradigma moderno; a terceira seção mostra a transição desse paradigma para o paradigma da complexidade; e a quarta seção situa os estudos organizacionais nesse novo paradigma. A partir daí, temos outras 3 seções: uma mostra a trajetória histórica da heterogeneidade; outra evidencia como ela é conceituada na TAR; e a última aborda a mediação como foco de análise da heterogeneidade na TAR. A ênfase nestas 3 últimas seções recai sobre o argumento de como a heterogeneidade pode constituir uma alternativa epistemológica para os estudos organizacionais. $\mathrm{O}$ artigo se encerra com nossa conclusão.

\section{A CRISE DO PARADIGMA MODERNO}

No paradigma moderno, postula-se a natureza como objeto racional a ser conhecido, passivo de dominação e controle, e o ser humano como sujeito racional desse conhecimento (SANTOS, 2000). A concepção específica do conhecimento, nessa perspectiva, é regulada pela atividade racional e soberana de um sujeito neutro, separado de seu objeto, e por uma natureza passiva, inteiramente submetida a relações determinísticas.

O paradigma moderno só aceita como válido o conhecimento objetivo e explicativo, excluindo o conhecimento intersubjetivo, descritivo e compreensivo. Assim, conhecer significa reduzir o complexo à simplicidade de suas determinações, apoiando-se na observação sistemática das partes, a partir das quais se pode ascender a um conhecimento rigoroso e mais profundo, utilizando a matemática como modelo de representação e organização do real (SANTOS, 2000).

Essa perspectiva concede ao conhecimento científico uma natureza totalitária e excludente de outros saberes que não se pautaram pelos pressupostos da observação sistemática e objetiva. E, ao se basear em objetivos emancipatórios e regulatórios, determinou que o papel atribuído ao conhecimento científico seria dominar e controlar, primeiro a natureza, depois o homem e a sociedade (PLASTINO, 2001).

Sabe-se que o desenvolvimento inicial das ciências sociais e das ciências humanas ocorreu com base nos métodos oriundos das ciências naturais, com foco, preponderantemente, no controle. Entretanto, a dificuldade da adequação de estudar os fenômenos sociais como fenômenos naturais acabou por realçar a crise do paradigma moderno. Santos (2000) afirma que a condição sociocultural do final do século XX é caracterizada pela absorção do pilar da emancipação pelo pilar da regulação, decorrente dos excessos e déficits da modernidade confiada à ciência moderna (racionalidade cognitivo-instrumental) e ao direito moderno (princípio de mercado). $O$ autor afirma que a crise do paradigma dominante é o resultado interativo de uma pluralidade de condições, dentre as quais ele destaca: 1) o aprofundamento das análises teórico-empíricas permitiu ver as fragilidades dos pilares em que o conhecimento científico se funda; 2 ) as implicações constatadas pela interferência estrutural do sujeito no objeto observado expõe a dúvida da neutralidade do conhecimento científico gerado; 3) o rigor matemático em que o paradigma moderno se assenta na realização das análises científicas não assegura proposições irrefutáveis; 4) os progressos nos domínios da microfísica, da química e da biologia nos últimos anos, trouxe à tona a lógica da auto-organização 
dos sistemas abertos em uma situação de não equilíbrio e impossibilidade de análises científicas lineares. Essas condições das inovações teóricas, entre tantas outras, propiciam uma profunda reflexão epistemológica sobre o conhecimento científico, colocando o modus operandi do paradigma moderno cada vez mais em dúvida.

As novas reflexões científicas criticam a falta de fundamentos dos postulados básicos do paradigma moderno e sua pretensão de exclusividade na produção de conhecimento válido. Essas reflexões apontam que o caráter totalitário desse paradigma transformou a humanidade em refém da dinâmica científica, por meio da convergência entre o paradigma moderno e o capitalismo, que passou a atender aos interesses do mercado, ameaçando gravemente não só a qualidade de vida dos homens, mas sua própria sobrevivência. Desenvolveu-se, portanto, no interior desse paradigma moderno, um posicionamento antipositivista, mostrando que a separação do sujeito e do objeto nas análises científicas que esse paradigma defende, não gera conhecimento neutro e independente da realidade que investiga. Entretanto, o conhecimento gerado é, ao contrário, instrumento de poder e dominação dessa mesma realidade investigada (PLASTINO, 2001).

Santos (2000, p. 71) afirma que "a análise das condições sociais, dos contextos culturais, dos modelos organizacionais de investigação científica, antes acantonada no campo separado e estanque da sociologia da ciência, passou a ocupar papel de relevo na reflexão epistemológica". Para o autor, um paradigma emergente não pode ser apenas científico, tem de ser também um paradigma social, considerando todas as formas de resistências e contrárias às formas hegemônicas de geração de conhecimento. Há necessidade de uma revisão radical da distinção entre sujeito e objeto. $\mathrm{O}$ objeto é a continuação do sujeito por meio de suas inter-relações cotidianas. Para Plastino (2001, p. 36), "o real estático e eterno suposto pelo paradigma moderno é substituído, [...] por uma totalidade aberta, em perpétuo devir, incluindo nesse processo a própria participação".

A crise do paradigma moderno evidencia um caminho de ajustes na ciência e na construção do conhecimento, direcionando-o para maior abrangência do saber científico. Essa abrangência leva em conta a inclusão de outros elementos da realidade e a consideração da inter-relação entre esses elementos, para que esta possa se adequar ao contexto complexo das ciências sociais. Portanto, a partir da emergência de um novo paradigma, torna-se cada vez mais evidente a necessidade de aprofundamento da crítica ao paradigma moderno e de seus pressupostos epistemológicos, principalmente aos seus dualismos: ser humano/natureza, natureza/cultura e sujeito/objeto (MORIN, 2008). A ideia básica defendida por Morin (2008) é que não se pode conhecer a essência do real porque a realidade não se deixa reduzir à racionalidade superficial dos métodos científicos modernos.

O autor assegura que, ao aplicar a visão científica clássica à sociedade, denominada por ele paradigma de simplificação, produzem-se como resultado, exclusivamente determinismos, tolhendo a autonomia dos indivíduos e suas atuações perante as coletividades das quais fazem parte. Além disso, Morin (2008) enfatiza que, ao analisar o que se passa atualmente no domínio das ciências sociais, é possível visualizar duas sociologias em uma: a que tem pretensão científica (determinista), que elimina a ideia de atores, de sujeitos, uma ciência privada da vida; e a que resiste a essa cientificação, que trata de atores, de sujeitos, de tomada de consciência, de problemas éticos, considerada pelos cientistas destituída de fundamento científico.

Para ser capaz de pensar a realidade antropossocial em sua complexidade, precisa-se de métodos que saibam distinguir as diversas complexidades inerentes à realidade. De modo que não separe e dissocie essas complexidades, mas que saibam promover a comunicação do que é distinto, respeitando seu caráter multidimensional, de dimensões biológica, social e individual e que permita o diálogo das questões intrínsecas ao sujeito e à sua autonomia. É nesse sentido que se propõe a inserção do pensamento complexo nas ciências sociais, segundo o qual se torna possível reconhecer na sociedade não apenas processos, regularidades, aleatoriedades, mas também seres, entes, indivíduos, contribuindo para as promoções das aspirações individuais, coletivas e étnicas de autonomia e de liberdade. Assim, a resposta da ciência à questão social será sua contribuição para as profundas aspirações da humanidade.

\section{DO PARADIGMA DA SIMPLIFICAÇÃO PARA O PARADIGMA DA COMPLEXIDADE}

O paradigma da simplificação se caracteriza pelos princípios de generalidade (do particular para o geral), redução (do todo em partes) e separação (do sujeito que investiga para o objeto que é investigado). Esses princípios definem a inteligibilidade própria do conhecimento científico clássico e produz, em decorrência, uma concepção simplificadora do universo (MORIN, 2008). $O$ quadro 1 apresenta algumas características desse paradigma. 


\section{Quadro 1}

\section{Características do paradigma da simplificação da ciência clássica}

\begin{tabular}{ll}
\hline 1 & Princípio de universalidade: “só há ciência no geral”. Expulsão do local e do singular como contingentes ou residuais. \\
\hline 2 & Eliminação da irreversibilidade temporal, e, mais amplamente, de tudo o que é eventual e histórico. \\
\hline 4 & $\begin{array}{l}\text { Princípio que reduz o conhecimento dos conjuntos ou sistemas ao conhecimento das partes simples ou unidade elementares } \\
\text { que os constituem. }\end{array}$ \\
\hline 5 & $\begin{array}{l}\text { Princípio que reduz o conhecimento das organizações aos princípios de ordem (leis, invariâncias, constâncias etc.), inerentes a } \\
\text { essas organizações. }\end{array}$ \\
\hline 6 & $\begin{array}{l}\text { Princípio da causalidade linear, superior ou exterior aos objetos. } \\
\text { devem a nossa ignorância. Assim, em função dos princípios 1, 2, 3, 4, e 5, a inteligibilidade de um fenômeno ou objeto complexo }\end{array}$ \\
\hline 7 & se reduz ao conhecimento das leis gerais e necessárias que governam as unidades elementares do qual é constituído. \\
\hline 8 & $\begin{array}{l}\text { Princípio da separação absoluta entre o objeto e o sujeito que o percebe/concebe. A verificação por observadores/ } \\
\text { experimentadores diversos é suficiente não só para atingir a objetividade, mas também para excluir o sujeito cognoscível. }\end{array}$ \\
\hline 9 & Eliminação de toda a problemática do sujeito no conhecimento científico. \\
\hline 10 & Eliminação do ser e da existência por meio da quantificação e da formalização. \\
\hline 12 & A autonomia não é concebível. \\
\hline 13 & Princípio da confiabilidade absoluta da lógica para estabelecer a verdade intrínseca das teorias. Toda contradição aparece \\
\hline
\end{tabular}

Fonte: Adaptado de Morin (2008).

Com base nas características do paradigma de simplificação, para conhecer um objeto é necessário conhecer sua situação no espaço (posição, velocidade), suas qualidades físicas (massa, energia), suas propriedades químicas e as leis gerais que nele agem. Morin (2008) esclarece que, ao seguir esses princípios simplificadores, os objetos tendem incessantemente a cair nos trilhos reducionistas, mutilantes e manipuladores da realidade investigada.

Diante disso, como atuar em sistemas complexos tendo por base uma visão reducionista dos fenômenos? Por um lado, Descartes (1980), no Discurso do método, determina os preceitos cartesianos que caracterizam a abordagem cartesiana. Por outro lado, em oposição a esses preceitos, Le Moigne (1977) determina os preceitos sistêmicos baseados no "novo discurso do método" que caracteriza a abordagem sistêmica. Esses preceitos são resumidos no Quadro 2.

\section{Quadro 2}

\section{Resumo dos preceitos cartesianos e sistêmicos}

\section{Preceitos cartesianos}

Evidência: a verdade é única e só existe se puder ser provada.

Reducionismo: divisão dos problemas nas menores partes possíveis para proceder à sua resolução.

Causalista: institui-se uma hierarquia estrutural para resolução dos problemas, iniciando-se pelas partes mais simples e fáceis e ascendendo para as mais difíceis e complexas.

Exaustividade: retoma os três primeiros preceitos e faz uma última análise do objeto, considerando que nada mais existe para ser explorado.

\section{Preceitos sistêmicos}

Pertinência: a percepção do objeto está diretamente relacionada à intenção do sujeito.

Globalismo: é consciente de que o objeto investigado faz parte de um todo maior, por isso a importância de compreender o funcionamento da parte em relação ao ambiente.

Teleológico: busca compreender o comportamento do objeto, sem o objetivo de explicá-lo em relação à estrutura física do objeto.

Agregatividade: considera que toda representação é influenciada pela visão de mundo do observador. Por isso, muitos aspectos podem ser omitidos.

Fonte: Elaborado pelos autores. 
A partir desses preceitos, justifica-se a necessidade de uma abordagem complexa para investigar os sistemas sociais (organizações), tendo em vista que são sistemas complexos que apresentam características que se entrelaçam e se complementam, sempre gerando novos comportamentos e formas de organização. O paradigma reducionista procura a explicação no nível dos elementos de base, enquanto que a complexidade se debruça no nível de princípio paradigmático, isto é, deve ser crítica em relação às noções que ela própria constrói, como é o caso das causalidades recíprocas, dos níveis organizacionais e das autonomias emergentes das partes em relação ao todo. Em síntese, para Morin (2008), a complexidade é insimplificável. 0 objeto é conquistado pelos sujeitos em uma atividade interativa de construção, em que tanto o objeto afeta a percepção do observador como o observador participa da existência do objeto. O paradigma da complexidade, como um todo, possibilita uma melhor compreensão de sistemas dinâmicos não lineares.

Capra (1996) também enfatiza que as mudanças de paradigmas influenciam o modo de observar as relações na natureza. Com isso, a observação dos elementos da natureza vai depender do observador e de sua percepção e interação com o meio. O modo como ele observa o meio ambiente pode diferir de outro observador, pois depende dos questionamentos em relação ao objeto observado. Assim, ao reconhecer que todas as teorias são limitadas e aproximadas e a ciência nunca pode fornecer uma compreensão completa e definitiva dos fenômenos estudados cientificamente, Morin e Le Moigne (2000) indicam que é preciso conceber uma nova forma de pensamento, denominada pensamento complexo ou da complexidade, que se contrapõe à visão analítica de mundo, uma vez que:

[...] tal concepção mecanicista do mundo ainda está na base da maioria de nossas ciências e continua a exercer uma enorme influência em muitos aspectos de nossa vida. Levou à bem conhecida fragmentação em nossas disciplinas acadêmicas e entidades governamentais e serviu como fundamento lógico para o tratamento do meio ambiente natural como se ele fosse formado de peças separadas a serem exploradas por diferentes grupos de interesses (CAPRA, 2006, p. 37).

Essa nova forma de pensamento pressupõe uma visão sistêmica de mundo, apresentada inicialmente pela obra de Bertalanffy (1977), na qual desenvolveu a Teoria Geral dos Sistemas (TGS) e o conceito de sistema aberto, entendido como um conjunto de elementos em interação entre si e com o ambiente. O autor distinguiu a TGS, que busca compreender os fenômenos dentro do contexto de um todo maior da ciência clássica que se caracteriza pelo reducionismo científico. Sua fundamentação teórica pressupõe múltiplos enfoques (modelos de sistemas mais ou menos avançados e complexos) que podem ser aplicados na resolução de problemas dentro da TGS.

Para Morin (2008), a emergência sistêmica apresenta três pressupostos: 1) o todo é mais do que a soma das partes: o sistema está além de sua forma global, possui algo mais do que seus componentes considerados de forma isolada - sua organização, a própria unidade global, as qualidades e propriedades emergentes da organização e da unidade global; 2) o todo é menos do que a soma das partes: toda organização comporta diversos níveis de subordinação quanto aos componentes. Em todo sistema, há coesões sobre as partes. Estas impõem restrições e servidões, que o fazem perder ou inibem qualidades e propriedades; 3 ) a formação do todo e as transformações das partes: um sistema é um todo que toma forma ao mesmo tempo que seus elementos se transformam. A ideia de emergência é inseparável da ideia de criação de uma forma nova que constitui um todo.

A TGS reagiu ao reducionismo no e pelo "holismo", ou ideia do "todo". Entretanto, o pressuposto holístico do pensamento sistêmico, ao acreditar que estaria ultrapassando o reducionismo, operou de fato uma redução no todo, ocasionando não apenas cegueira sobre as partes enquanto partes, mas miopia sobre a organização enquanto organização e ignorância da complexidade no interior de unidades globais (MORIN, 2005). Questões como diferenciação, evolução e organização dos fenômenos estudados são aspectos complexos intransponíveis aos métodos científicos praticados por esse paradigma.

Questiona-se a ausência do termo organização na definição de sistema, que é considerado unidade global organizada de inter-relações entre elementos, ações ou indivíduos (MORIN, 2008). O autor argumenta que os conceitos de organização e sistemas estão ligados pelas inter-relações, havendo uma reciprocidade circular relacionada a tipos e formas de ligações entre os elementos ou indivíduos e o todo. O sistema remete às unidades complexas de "todos" inter-relacionados, às suas características e propriedades fenomenais, enquanto organização se refere à disposição de partes "dentro, em e por um todo". Nesse sentido, a organização é o conceito essencial, o nó que possibilita inter-relações entre as partes e essas com o sistema geral. 
A organização transforma uma diversidade separada em uma forma global (gestalt). E, ao possibilitar contínuas mudanças de forma, a organização forma (um todo) a partir da transformação (dos elementos) (MORIN, 2008).

Segundo Morin (2008), a TGS acentuou pertinentemente a ideia de que a abertura é necessária a conservação, à renovação, à sobrevida dos sistemas vivos, mas não realçou seu caráter organizacional, definindo a ideia de abertura simplesmente em alternativa de exclusão à ideia de fechamento. Ao contrário dessa perspectiva da teoria de sistemas, os termos abertura e fechamento, considerando-os organizacionalmente, não estão em oposição absoluta. Atribui-se, portanto, a Morin a compreensão de que para algo ser considerado sistema precisa ser organizado: a organização liga, forma, transforma, mantém, estrutura, ordena, fecha e abre um sistema.

Destarte, houve uma mudança na forma de compreender as relações e a organização de um sistema. Os elementos de um sistema não se relacionam apenas de forma causal e linear, mas são capazes de se relacionar também de forma retroativa e recursiva, apresentando mais de uma forma ou padrão de relacionamento sistêmico. A complexidade, não está relacionada apenas à quantidade de elementos existentes em dado sistema, mas às ações e relações que se estabelecem entre eles, bem como com o ambiente (MISOCZKY, 2003), estabelecendo a dinâmica de evolução e transformação.

A concepção sistêmica da vida não deve pressupor sistemas como seres isolados, mas como partes de padrões integrados. São conjuntos de significados cujas características mais relevantes não estão em suas partes, mas na maneira como estas se relacionam com o todo. Esse enfoque surge, de certo modo, da física quântica, onde as partículas subatômicas não possuem significados isoladamente, podendo ser entendidas apenas como interconexões. Partes estão organizadas em teias de relações que se interligam, não podendo ser analisadas isoladamente, mas por meio de suas relações mútuas, nas quais estão perfeitamente integradas para o funcionamento do todo (CAPRA, 1996).

A abordagem proposta por Morin (2008) conduz ao pensamento complexo a partir de conceitos inacabados ou em constante construção. Deixa de estabelecer relações entre sistemas fechados dicotômicos para pensar em totalidades integradoras. Sua prerrogativa não é fazer uma teoria geral abrangendo partes, mas considerar a riqueza do real à luz da complexidade sistêmico-organizacional. O método visa a unir noções que se excluem na perspectiva paradigmática convencional ou, até certo ponto, na TGS, como simplificação x redução; uno x múltiplo; todo x partes; ordem $x$ desordem; sujeito x objeto; observador $\mathrm{x}$ sistema observado, e assim por diante.

O paradigma da complexidade consiste em reconhecer as incertezas e contradições como características inerentes aos conhecimentos, evidenciando a ignorância como intrínseca aos processos da pesquisa científica. Contudo, não visa a abandonar os pressupostos da ordem, da lógica e da verdade, mas integrá-los em concepções mais ricas e abrangentes que reconhecem esses pressupostos como partes elementares da formação e transformação da ciência, assim como a dúvida e a ignorância. O Quadro 3 apresenta os princípios do paradigma da complexidade.

\section{Quadro 3}

\section{Princípios do paradigma da complexidade}

\begin{tabular}{|c|c|}
\hline Princípio & Descrição \\
\hline \multirow{3}{*}{ Princípio sistêmico } & Inter-relaciona o conhecimento das partes ao conhecimento do todo. Considera \\
\hline & impossível conhecer as partes sem conhecer o todo, tanto quanto conhecer o todo sem \\
\hline & conhecer, particularmente, as partes. A ideia sistêmica, oposta à ideia reducionista, é que \\
\hline \multirow[t]{2}{*}{ ou organizacional } & o todo é mais do que a soma das partes. O todo é igualmente, menos que a soma das \\
\hline & partes, cujas qualidades são inibidas pela organização do conjunto. \\
\hline \multirow{2}{*}{ Princípio hologramático } & Põe em evidência o aparente paradoxo das organizações complexas, em que não \\
\hline & apenas a parte está no todo, como o todo está inscrito na parte. \\
\hline \multirow{2}{*}{ Princípio do anel retroativo } & Permite o conhecimento dos processos autorreguladores. Esse princípio rompe com o \\
\hline & princípio da causalidade linear: a causa age sobre o efeito e o efeito age sobre a causa. \\
\hline \multirow{3}{*}{ Princípio do circuito recursivo } & Ultrapassa a noção de regulação com as de autoprodução e auto-organização. É um \\
\hline & circuito gerador em que os produtos e os efeitos são produtores e causadores daquilo \\
\hline & que o produz. \\
\hline
\end{tabular}


Continuação

\begin{tabular}{|c|c|}
\hline Princípio & Descrição \\
\hline $\begin{array}{l}\text { Princípio de auto-eco-organização } \\
\text { (autonomia/dependência) }\end{array}$ & $\begin{array}{l}\text { Os seres vivos são seres auto-organizadores que não param de se autoproduzir e, por } \\
\text { isso mesmo, despendem energia para manter sua autonomia. Um aspecto-chave da } \\
\text { auto-eco-organização viva é que ela se regenera permanentemente a partir da morte } \\
\text { de suas células. }\end{array}$ \\
\hline Princípio dialógico & $\begin{array}{l}\text { Une dois princípios ou noções que deviam excluir-se reciprocamente, mas são } \\
\text { indissociáveis em uma mesma realidade. Sob as mais diversas formas, a dialógica } \\
\text { está constantemente em ação nos mundos físico, biológico e humano. Esse princípio } \\
\text { permite assumir racionalmente a inseparabilidade de noções contraditórias para } \\
\text { conceber um mesmo fenômeno complexo. }\end{array}$ \\
\hline $\begin{array}{l}\text { Princípio da reintrodução daquele que } \\
\text { conhece em todo conhecimento }\end{array}$ & $\begin{array}{l}\text { Opera a restauração do sujeito nos processos de construção de conhecimento e revela } \\
\text { o problema cognitivo central: da percepção à teoria científica, todo conhecimento } \\
\text { é uma reconstrução/tradução feita por uma mente/cérebro, em uma cultura e em } \\
\text { determinado horizonte temporal. }\end{array}$ \\
\hline
\end{tabular}

Fonte: Adaptado de Morin (2008).

Morin (2008) enfatiza que o paradigma da complexidade não "produz" nem "determina" a inteligibilidade. Pode somente estimular a estratégia/inteligência do sujeito pesquisador a considerar a complexidade da questão estudada, incitando-o: a) a distinguir e fazer comunicar em vez de isolar e de separar; b) a reconhecer traços singulares, originais e históricos do fenômeno em vez de ligá-los pura e simplesmente a determinações ou leis gerais; c) a conceber a unidade/multiplicidade de toda entidade em vez de separá-la em categorias ou de homogeneizá-la em indistinta totalidade; e d) a dar conta dos caracteres multidimensionais de toda a realidade estudada. A ideia de integração e interdependência exigiu novas formas de investigar os processos evolutivos dos sistemas complexos. Enquanto a abordagem reducionista se baseia na análise por meio da explicação dos componentes do objeto, a abordagem complexa se baseia na compreensão do objeto para interpretá-lo e antecipar-se ao seu comportamento (LE MOIGNE, 1977).

Nos estudos organizacionais, a preocupação em explicar a existência e o desenvolvimento das organizações a partir de uma perspectiva sistêmica cresce cada vez mais, justificada principalmente pela constatação de que os agentes e seus processos de interação são os elementos fundamentais para seu desempenho e sobrevivência. Além disso, as abordagens mais complexas se justificam na medida em que propõem novas interpretações para a realidade organizacional. Contudo, considerando as peculiaridades dos fenômenos no escopo das organizações, verifica-se a complexidade, em sentido literal, que é a adoção de uma abordagem complexa para compreensão da estrutura e funcionamento desses fenômenos.

\section{OS ESTUDOS ORGANIZACIONAIS À LUZ DO PARADIGMA DA COMPLEXIDADE}

O surgimento de várias correntes paradigmáticas possibilitou o desenvolvimento de uma multiplicidade de abordagens metodológicas nos estudos organizacionais. Morgan (2002) afirma que as organizações e os problemas organizacionais passaram a ser vistos e entendidos de diferentes formas e, cada uma dessas formas, ao limitar sua maneira de ver e de pensar, também limitou sua área de ação e, em decorrência, sua eficácia. Burrell e Morgan (1979), por exemplo, fizeram um mapeamento no campo dos estudos organizacionais e identificaram quatro paradigmas que são utilizados na teoria social de maneira geral e na teoria das organizações de maneira particular. Uma de suas principais conclusões é a acentuada oposição entre esses paradigmas, o que causou uma fragmentação de pontos de vista e iniciou-se um debate sobre a incomensurabilidade entre eles.

Em decorrência dessa incomensurabilidade entre diversos paradigmas, têm-se acentuado, no âmbito dos estudos organizacionais, os debates e embates entre pesquisadores acerca da validade e eficácia dos métodos e pressupostos teóricos utilizados (SILVA e ROMAN NETO, 2010). Um dos argumentos centrais é a necessidade de adotar abordagens plurais que possibilitem maior compreensão da riqueza dos fenômenos sociais inseridos nos contextos organizacionais, ampliando os conhecimentos inerentes a esse campo de investigação. Em decorrência dessa pluralidade de abordagens, a área de Administração cada vez mais é reconhecida como multiparadigmática (LEÃO, MELLO e VIEIRA, 2009), buscando compreensão dos fenômenos 
organizacionais não somente pelos métodos científicos tradicionais que geram conhecimentos objetivos e explicativos, mas também por meio de conhecimentos intersubjetivos e compreensivos (GODOI, BANDEIRA-DE-MELO e SILVA, 2010).

O pensamento complexo surge como estratégico diante dessas novas perspectivas organizacionais, principalmente pelo seu caráter multidisciplinar, já que busca entender as relações necessárias e interdependentes de todos os aspectos da vida humana, integrando os diferentes modos de pensar. Considera-se uma abordagem de pensamento que leva em conta todas as influências recebidas, internas e externas e que enfrenta as incertezas e contradições sem deixar de conviver com a solidariedade dos fenômenos existentes (PETRAGLIA, 2002). As empresas, por exemplo, deixam de ser vistas em atuações isoladas em seus mercados para ser compreendidas nos diversos contextos de interação com clientes, fornecedores, concorrentes, agentes reguladores, dentre outros atores que corroboram a compreensão do todo que são os diversos segmentos produtivos modernos.

A noção-base de sistemas, no âmbito do pensamento complexo, considera-os abertos e em interações com ambiente onde estão inseridos, a partir de um conjunto de relações de interdependências que estabelecem seu comportamento. Assim, Morgan (2002, p. 260) destaca que a essência dos pontos de vista da complexidade é que

[...] sistemas complexos e não lineares, como ecologias ou organizações, são caracterizados por múltiplos sistemas de interação que são ao mesmo tempo ordenados e caóticos. Devido a esta complexidade interna, perturbações aleatórias podem produzir eventos imprevisíveis e relações que repercutem em todo o sistema, criando novos padrões de mudança. O mais surpreendente, no entanto, é que apesar de toda imprevisibilidade, uma ordem coerente sempre emerge da aleatoriedade e do caos superficial (MORGAN, 2002, p. 260).

A interação gera realimentações que podem ser positivas ou negativas, criando autorregulações regenerativas, que por sua vez criam novas propriedades que influenciam, reciprocamente, o todo e as partes do sistema. Morgan (2002) ressalta que se um sistema tem grau suficiente de complexidade interna, a aleatoriedade, diversidade e instabilidade tornam-se recursos para mudanças e tem-se como resultado natural a emergência de uma nova ordem. Atualmente, essas interações cada vez mais são percebidas nas organizações e seus ambientes. Suas implicações para a moderna Administração dão origem a algumas questões-chave nos estudos organizacionais: repensar o que tem sido dito sobre as organizações, especialmente a natureza de suas hierarquias e de seus controles; compreender melhor o que é a arte de administrar e mudar contextos; aprender como usar pequenas mudanças para criar grandes efeitos; viver a transformação contínua e a ordem emergente como um estado natural; e estar aberto para novas metáforas que possam facilitar os processos de auto-organização.

Por outro lado, Guerreiro Ramos (1981) afirma que a teoria organizacional em uso não consegue proporcionar uma compreensão exata da complexidade da análise e desenho dos sistemas sociais. Isso por apresentar as seguintes limitações: 1) o conceito de racionalidade predominante na teoria das organizações conduz ao entendimento de que o comportamento econômico constitui a totalidade da natureza humana; 2) essa abordagem não distingue o significado substantivo do significado formal da organização; 3) não trabalha com a ideia clara do que compreende a interação simbólica no conjunto dos relacionamentos interpessoais; e 4) se apoia no pressuposto de que o homem é apenas um componente da força de trabalho, considerado como elemento de custo para as organizações. Guerreiro Ramos (1981) aponta para a necessidade de desenvolvimento de uma nova abordagem psicológica para a ciência das organizações, considerando, prioritariamente, seus sistemas cognitivos. Isso corrobora Morin (2008), quando afirma a necessidade de pensar a realidade antropossocial em sua complexidade e de um método que saiba promover a comunicação do que é distinto, respeitando o caráter multidimensional das coisas.

Boeira e Vieira (2010) destacam que a construção da teoria organizacional tem sido dominada pelas perspectivas funcionalistas, segundo as quais as organizações são vistas como máquinas ou organismos vivos. Tal visão pressupõe a possibilidade de decomposição de cada organização em conjuntos de variáveis relacionadas, como as estruturais, técnicas, políticas, culturais, humanas, ecológicas dentre outras, mas os autores alertam, contrariamente a essa visão - que as dimensões estruturais e técnicas das organizações são, simultaneamente, humanas, políticas e culturais. Assim, para pensar as realidades organizacionais em suas complexidades, necessita-se adotar abordagens que saibam promover análises considerando e respeitando o caráter multidimensional das organizações.

Serva (1992) enfatiza que trabalhar com o paradigma da complexidade, sobretudo sua lógica pluralista, pode ser frutuoso para aqueles que se aventuram na análise organizacional. Morgan (1996), segundo ele, faz claras referências ao paradigma 
da complexidade, utilizando a lógica da autopoiese definida por Varela, ao enfatizar o fluxo de transformação que as organizações enfrentam, na qual a constituição da identidade da organização ganha outros contornos, relativizando suas fronteiras, onde cada área que interage com o ambiente da organização faz parte dela mesma. Outras vertentes da configuração do fluxo em transformação citadas por Morgan (1996), segundo Serva (1992), são: a plena utilização da lógica da causalidade mútua, que demonstra as vantagens auferidas com o emprego de modelos circulares de interação para conceber as relações organização-ambiente; e que a imagem do fluxo de transformação permitiria fornecer indicações sobre a maneira como a organização poderia começar a influenciar efetivamente a natureza das mudanças das quais faz parte.

Jean-François Chanlat também, segundo Serva (1992), reforça a relevância eminente da complexidade ao classificar as teorias das organizações em dois paradigmas, o funcionalista, que trata preferencialmente da integração, do consenso, da coordenação funcional, enfim, da ordem; e o crítico, que privilegia o conflito, a mudança, isto é, a desordem. Nesse contexto, faz-se um apelo à adoção do paradigma da complexidade nos estudos organizacionais, ao enfatizar os seguintes aspectos: ordem, desordem, auto-organização a partir do ruído, acaso organizador, catástrofe, social-histórico, entre outros (SERVA, 1992). Dentre as características das organizações como fenômenos sociais aplicados que as tornam aptas a ser investigadas à luz do paradigma da complexidade, algumas têm-se destacado:

- As organizações são consideradas sistemas abertos que estão inseridos em um ambiente dinâmico nos quais os seres humanos desempenham papéis primordiais, além de manter relações com uma variedade de agentes (fornecedores, clientes internos e externo, concorrentes, agentes reguladores) que possuem autonomia e dependência. Desse modo, os subsistemas organizacionais estão conectados por ações interdependentes - a ação de um agente interfere na ação de outro e vice-versa;

- Os agentes interagem dentro do sistema e fazem nascer as propriedades emergentes, aquelas que somente aparecem da interação das partes. A complexidade do sistema organizacional é determinada a partir da conectividade entre a agregação desses agentes: quanto mais o sistema desenvolver sua complexidade, mais poderá desenvolver sua autonomia e mais dependências múltiplas terá;

- Os agentes organizacionais são autônomos e possuem consciência de suas habilidades, informações e possibilidades de atuação em determinadas situações;

- O controle dos sistemas organizacionais surge com o intuito do ente autônomo enxergar suas limitações e buscar, na interação entre as partes, sua superação e evolução;

- Existem regras formais que regulam os sistemas organizacionais. Geralmente essas regras são restritivas, contudo, os agentes dotados de autonomia produzem regras informais para articular os objetivos das organizações com os objetivos individuais.

Por outro lado, Serva (1992) destaca três limites ao emprego do paradigma da complexidade no estudo de organizações que são relevantes e devem ser considerados:

- O primeiro diz respeito à utilização da autopoiese na imagem do fluxo em transformação, que poderia fornecer indicações de como se poderia influenciar as mudanças com as quais se defronta a organização, o que não significa dizer que se teria automaticamente a capacidade efetiva de fazê-lo;

- O segundo provém da própria natureza do conhecimento científico que, por mais bem elaborado que possa parecer, ele sempre será insuficiente, precário e impreciso em face do real, assim, o uso do paradigma da complexidade nos estudos organizacionais nunca deverá ser mitificado como panaceia para desvendar todos os mistérios do fenômeno organizacional;

- E a transdisciplinaridade pretendida pelos pesquisadores, na qual a transposição de conceitos deve ser feita com extremo rigor e cuidado, levando em conta as dificuldades epistemológicas devido aos contextos próprios de cada ciência, o sentido e as particularidades quando da criação dos conceitos no interior daquela ciência específica e sua viabilidade no campo social.

Além dessas características e propriedades dos sistemas complexos que impõem limites ao emprego do paradigma da complexidade aos estudos organizacionais, existem outros elementos que também dificultam esse emprego. Um deles consiste na relação estabelecida pelo observador ao fenômeno investigado. Capra (1996, p. 49) diz que a descrição de um objeto depende da percepção, dos métodos de observação e da medição utilizados. "o que observamos não é a natureza em si, mas a natureza exposta ao nosso método de questionamento". Outro elemento que vale a pena destacar é que a percepção da realidade organizacional como fenômeno social complexo exige a construção de conhecimentos e instrumentos que sejam adequados na investigação das organizações. Ao ser compreendidas por meio de um conjunto de características complexas, as organizações passam a ser vistas como sistemas com comportamentos muito peculiares, cujas dinâmicas estabelecidas se tornam muito específicas e contextuais, dependendo sempre de suas interações e atuações. 
Como os sistemas complexos, as organizações operam entre a ordem e a desordem, de modo que em cada fase de instabilidade proporcionada pelas ameaças externas se verifica, simultaneamente, presença de caos e de equilíbrio, a definição dos graus de estabilidade e instabilidade do sistema organizacional como um todo se torna um desafio ainda praticamente insuperável. A ciência da complexidade, ao buscar a compreensão da dinâmica assumida pelas organizações como fenômenos sociais, visando à antecipação do seu comportamento a partir da compreensão de seu funcionamento, deixa em suspenso toda a conectividade presumida entre as partes e o todo que forma e transforma cotidianamente as organizações.

Torna-se sobremaneira utópico adotar abordagens que permitam a construção de um conhecimento intersubjetivo e compreensivo que enfatize as organizações em sua complexidade. As limitações do uso do paradigma da complexidade apresentadas por Serva (1992), apoiadas no que diz Morin (2008), ao enfatizar que o paradigma da complexidade não "produz" nem "determina" a inteligibilidade, continuam relevantes para os estudos organizacionais. Quando muito, esse paradigma tem somente incitado as estratégias de pesquisa a considerar as complexidades das questões estudadas, continuando a desafiar o pesquisador a como reconhecer os traços singulares, originais e históricos dos fenômenos e como ligá-los a determinações ou leis gerais. Na prática, as complexidades têm sido evidenciadas por meio de heterogeneidades organizativas e inter-relacionadas. Compreendê-las, contudo, continua a desafiar os estudos pautados no paradigma da complexidade. Reconceituar essas heterogeneidades, como tem sido discutido pela TAR, apresenta-se como alternativa epistemológica para avançar a partir das limitações deixadas até aqui pelos estudos que têm tentado compreender as complexidades organizacionais.

\section{TRAJETÓRIA HISTÓRICA DA HETEROGENEIDADE}

A simples composição por elementos ou partes de diferentes naturezas, constituindo seres diversificados e variados, como se pressupõe em um paradigma simplificador, não é suficiente para definir a ideia de heterogeneidade, principalmente quando discutida contemporaneamente. Sua origem "tem registros no Latim Medieval, mas somente no século XVII que ela começa a ser usada para significar diferença, relações incongruentes e anomalias" (HETHERINGTON, 1999, p. 60). Contudo, a ideia de complexidade não se desenvolveu, única e exclusivamente, em oposição às simplificações do fazer científico moderno e se aproximou das conceituações recentes de complexidade. Pelo contrário, heterogeneidade foi, cada vez mais, significando um conjunto muito específico de conceitos válidos para descrição das realidades cotidianas, estejam elas evidenciadas em redes ordenadas e estáveis ou em complexas tramas ininteligíveis.

Uma conceituação diferente da usualmente encontrada nos dicionários ou na concepção paradigmática moderna é que os esforços não só científicos, mas também das artes, da literatura e tantas outras formas de expressar conhecimento, preocuparam-se com o ordenamento das redes heterogêneas tanto quanto com o próprio conceito de heterogeneidade em si. A preocupação esteve, em boa medida, voltada à exploração de como as coisas heterogêneas são ordenadas segundo padrões que geram efeitos como organizações, desigualdades e poder (LAW, 1992). Até certo ponto, as mudanças ocorridas na compreensão dos modos de ordenar o que é heterogêneo implicam também uma mudança no conceito de heterogeneidade (HETHERINGTON, 1999). E essas mudanças têm implicações para o uso do termo na TAR e na compreensão das realidades organizacionais.

Há pelo menos cinco possibilidades de compreensão da heterogeneidade, como demonstrou Hetherington (1999). A primeira diz respeito ao conceito de heterogeneidade no período renascentista e sua perspectiva de linearidade, sendo o sujeito sinônimo de heterogeneidade material. A segunda interpretação o autor atribui ao período clássico e à ideia de que a heterogeneidade pode ser colocada sobre a mesa, medida e ordenada. Na perspectiva moderna, por seu turno, a heterogeneidade se transforma em um problema a ser evitado e neutralizado. Contemporaneamente, ao contrário, a heterogeneidade se torna uma fonte de agência a ser explorada pela interação dos sujeitos com o mundo material. Hetherington (1999) destaca, ainda, uma quinta posição, na qual a heterogeneidade pode ser vista não mais somente pelo olhar do sujeito, mas também pela perspectiva do objeto. O conceito da TAR se aproxima desta última, principalmente pelas complexas imbricações que humanos e nãos humanos formam nas distintas realidades cotidianas em que atuam.

No período renascentista, segundo a discussão de Hetherington (1999), a heterogeneidade estava diretamente relacionada à forma de ver. $\mathrm{O}$ olhar, apesar das formas curvas da superfície da visão, era abstraído matematicamente de maneira que simplificava as distorções, possibilitando uma percepção linear da realidade. Isso resulta em uma forma de ordenar em que as coisas eram vistas como simples representações tridimensionais. Nesse período, em consequência, tudo é similitude, pois as coisas não são desordenadas, diferentes ou alteres ao observador. Não faz sentido entender a heterogeneidade como 
diferença, pois há correspondência direta entre todas as coisas e entre sujeito e objeto. Ela é somente o plano ilustrativo em que é refletido o mundo material. Apesar dessa relação entre sujeito e objeto não ser considerada heterogênea, conforme a TAR usa o termo, o sujeito está ordenado dentro da própria rede de artefatos que ele naturalmente gera. De todo modo, uma relação simétrica se apresenta entre ambos.

No período clássico, a heterogeneidade torna-se algo que não mais é traduzido pelo olhar. Ela é algo separado da visão e que pode ser descrita e classificada. Em consequência, ela pode ser colocada sobre a mesa para ser contemplada, medida e ordenada. O sujeito não mais é heterogêneo e passa a ser desconectado do mundo das coisas. A materialidade heterogênea do mundo é álter ao sujeito. Ele define a si e, de maneira separada, das coisas materiais. Na relação sujeito objeto, o heterogêneo é uma qualidade atribuída pelo sujeito. Contudo, ele também é definido em relação à heterogeneidade do mundo (HETHERINGTON, 1999). Porém, fica pressuposto o hiato entre sujeito e objeto, sendo a relação entre ambos somente qualificante.

Na modernidade, para Hetherington (1999), a heterogeneidade se torna uma preocupação no desenvolvimento de conhecimento. "A ideia de erradicar ao invés de estudar a heterogeneidade e a desordem é uma importante parte do projeto em torno da qual a ideia de modernidade é fundada" (HETHERINGTON, 1999, p. 65, tradução nossa). Os modernos se esforçam para ter sob seus domínios a heterogeneidade, que continua sendo algo a ordenar, disposto e, preferencialmente, retirado do âmbito do conhecedor. Como mostrou Latour (1994a), o objeto perde seu caráter de multiplicidade, tornando-se sem importância. A heterogeneidade é internalizada pelo sujeito, não sendo mais revelada pelo objeto. $O$ heterogêneo significa aquilo que dificulta a ordem, portanto, precisa ser disciplinado, neutralizado e internalizado pelo sujeito. A eliminação do objeto impossibilita uma comparabilidade de proporcionalidade (simetria) entre ambos. É fácil situar a TAR em um polo oposto à perspectiva moderna.

Contemporaneamente, seguindo essa cronologia histórica, Hetherington (1999) entendeu que a perspectiva da similitude volta a ter espaço. Tanto quanto pela observação do sujeito como pela sua "cegueira". Se o período moderno estava "cego" para os aspectos inerentes à subjetividade, agora a "cegueira" passa a ser uma característica relevante da subjetividade. Desse modo, o interesse passa a recair sobre o desejo, a subjetividade descentralizada, o discurso e a intertextualidade, as técnicas de desconstrução, as diferenças como fonte de resistência, dentre outros elementos intrínsecos ao projeto pós-moderno. Muito do que é discutido nessa perspectiva foi evidenciado ao discutir a perspectiva da complexidade.

Contemporaneamente também está a TAR, e a possibilidade de analisar a heterogeneidade pelo modo como atuam os atores-redes, indo além de todas as perspectivas de heterogeneidades discutidas anteriormente. $\mathrm{O}$ ator-rede, na TAR, ao inter-relacionar atores e suas conexões, é, simultaneamente, "um ator cuja atividade consiste em entrelaçar elementos heterogêneos e uma rede que é capaz de redefinir e transformar aquilo que já está realizado" (CALLON, 1998, p. 156). Todo ator, para a TAR, é intrinsecamente qualificado pelas conexões que ele forma e é por elas formado. Assim, ele é ator e rede, simultaneamente, pois possui intrinsecamente a agência, ou seja, ele pode influenciar ou ser influenciado (SHAPIRO, 2005), mas é restrito e dependente de suas posições, interações e conexões em relação aos demais.

De modo geral, enquanto o período renascentista e a perspectiva mais contemporânea se relacionam, principalmente com o paradigma da complexidade, o período clássico e a modernidade se coadunaram, sobretudo, ao paradigma da simplificação. A heterogeneidade, da forma como pressuposta no contexto da simplificação ou complexidade, trata-se sobretudo de concepções estáticas da realidade. Para essas correntes, a heterogeneidade existe, pois, os seres, por meio de suas identidades estáveis e fixas, estabelecem inúmeras relações, sejam elas descritíveis ou não. Geralmente, a pergunta que se faz nos paradigmas da simplificação ou da complexidade é como os eventos foram praticados em suas diferentes formas por diversas e heterogêneas entidades. Já para a ideia de heterogeneidade, como é compreendida contemporaneamente na TAR, a pergunta a ser feita é como as práticas ocorreram e permitiram gerar diferentes combinações de materiais e formas (LAW e SINGLETON, 2014).

Ontologicamente, para a TAR, a heterogeneidade é sobretudo relacional. Heterogeneidade relacional consiste na unidade de análise fundamental. Isso porque as redes, diferente de serem embeddedness materiais e humanos (THOMPSON, 2003), são concretudes que perfazem múltiplas realidades (MOL, 2002) e que definem as materialidades cotidianas. Determinismo-voluntarismo, estrutura-agência, dentre outras polaridades desafiadoras de superação nos estudos organizacionais, perde relevância na medida em que, para a TAR, não passam de sociomaterialidades transladadas por redes de atores em movimentos múltiplos e heterogêneos, podendo ser percebidas devido à fixidez gerada, seja de caráter mais humano, seja de caráter mais material.

Desse modo, os estudos em que se baseiam as análises sobre redes, a partir da simplificação ou complexidade, pressupõem análises relacionais a partir das materialidades que compõem a simples realidade ou as complexas realidades. Ou seja, tomado 
a fixidez material ou social, traçam-se as múltiplas possibilidades relacionais para compreensão dessas materialidades. Por isso, dualismos como estrutura-agência tornam-se instransponíveis. Abordagens como a TAR, para além disso, compreendem a fixidez material e social como efeitos gerados pela realidade relacional. Isto é, a heterogeneidade relacional é a matéria-prima básica de análise, pois a heterogeneidade é a composição básica da realidade. Por isso, as análises de redes devem considerar não estáveis ou complexas realidades, mas multiplicidades ontológicas que são definidoras de diversas dualidades tão desafiadoras para os estudos empíricos.

Para Callon (1986), os atores-redes são formados por elementos heterogêneos, sejam eles humanos ou não humanos, quase sujeitos ou quase objetos, que são ligados mutuamente no curso de suas interações. Os atores-redes agem simultaneamente entrelaçando elementos heterogêneos e desconectando-os na medida em que outras transformações e redefinições ocorrem. A heterogeneidade não diz respeito somente a elementos ou partes de diferentes naturezas, constituindo seres diversificados e variados, mas se relaciona principalmente às infinitas possibilidades de agrupamentos, indiferentes de ser mais ou menos instáveis, mais ou menos duradouros, oriundos do trabalho de mediação entre natureza e sociedade (LATOUR, 1994a; LAW, 2011). Assim, a heterogeneidade da TAR emerge como uma possível abordagem epistemológica para os estudos organizacionais.

\section{A HETEROGENEIDADE DA TEORIA ATOR-REDE COMO POSSIBILIDADE EPISTEMOLÓGICA PARA OS ESTUDOS ORGANIZACIONAIS}

Para os estudiosos da abordagem do ator-rede, a defesa é que uma das maneiras de resolver a dicotomia do determinismo empiricista e da subjetividade das complexidades sociais é a abordagem do ator-rede. Para Latour (1992), os que defendem essa abordagem concordam que tanto a realidade empírica como as complexidades e subjetividades sociais que envolvem os sistemas sociais e técnicos são desenvolvidas por meio de negociações entre as pessoas, instituições e organizações. E o caminho para equilibrar essas abordagens está em também considerar os artefatos nas análises, em uma consideração simétrica (BLOOR, 2009) com os humanos.

A TAR é um "caminho mediador", pois não se prende na simplificação dos fenômenos, nem em suas complexidades, mas na hibridez (LATOUR, 1994b; LAW e SINGLETON, 2000). Em consequência, um ponto-chave da TAR consiste no novo entendimento do agente de mudança. A abordagem do ator-rede, desse modo, extrapolando o conceito convencional de ator de ambos os paradigmas, evidencia tal expressão para abarcar um conjunto heterogêneo de elementos - animados e inanimados, naturais ou sociais - que se relacionam de modo diverso, durante um período de tempo suficientemente longo, e que são responsáveis pela transformação - incorporação de novos elementos, exclusão ou redefinição de outros, reorientação das relações - ou pela consolidação da rede por eles conformada (CALLON, 1987). Nas palavras de Latour (1992, p. 175-176, tradução nossa), "não são só essas diferenças paradigmáticas que devem ser colocadas em xeque, é a própria condição de mundo que deve ser repensada". Os artefatos compõem grande parte dos laços sociais e eles contribuem, sobremaneira, para a simplificação e divisão em partes do mundo, mas ao mesmo tempo para conferir complexidade e dinamicidade à vida humana.

Desse modo, para Latour (2008), há necessidade de questionar as bases científicas e evidenciar uma nova forma de olhar os fenômenos de pesquisa. A principal justificativa é que os atores devem ser entendidos como redes, com capacidades de formar associações e dissociações. Só faz sentido se forem estudados simetricamente e via translações sucessivas que as associações e dissociações rotineiramente formam. Não faz sentido analisar as diversas caixas-pretas que historicamente os estudos científicos têm analisado. A base da TAR está em mostrar que somente as diferenças entre o que pode ser colocado dentro dessas caixas e o que continua aberto a futuras negociações é que precisa ser analisado.

Os novos rumos a ser percorridos nos estudos científicos são os que consideram, como Latour (1988, p. 158-172, tradução nossa) enumerou, que:

- Nada é, por si só, redutível ou irredutível a qualquer outra coisa. O que Latour chamou de princípio da irredutibilidade;

- Há apenas estados de forças ou fraquezas. Ou, mais simplesmente, há apenas ensaios. O entendimento de Latour (1988) é que o que não é nem redutível nem irredutível tem de ser testado, contado e medido. Como consequência, toda coisa pode ser a medida de qualquer outra. O que resiste aos estudos é considerado real;

- Desse modo, o real não é uma coisa entre outras, mas somente gradientes de resistência. Isso implica dizer para Latour (1988) que não existem diferenças entre o "real" e "irreal", o "real" e o "possível" e o "real" e o "imaginário"; 
- Nada é conhecido, somente realizado. Nesse sentido, nenhuma força pode, como muitas vezes é, ser apresentado, "conhecer a realidade", a não ser por meio da diferença que se cria ao resistir a outras;

- Uma forma é uma linha de frente de uma prova de força que a de-forma, trans-forma, in-forma ou a per-forma. Essa força somente pode ser considerada de maneira ensaísta. Em seu lugar, também se pode falar de "fraquezas", "inteléquias", "mônadas", ou mais simplesmente de "actantes";

- Nenhum actante é tão fraco que não possa inscrever outro. Dois actantes juntos se tornam um terceiro actante que pode mover mais facilmente, com isso, um actante só ganha força em associação com outros. Certos resultados de seu trabalho não podem voltar ao seu estado original;

- $\quad$ Além disso, como tudo está em jogo, não se pode dizer que um actante segue regras, leis ou estruturas, como também não se pode dizer que age sem elas. Ou seja, nada, por si só, é ordenado ou desordenado, único ou múltiplo, homogêneo ou heterogêneo, fluido ou inerte, humano ou não humano, útil ou inútil;

- Da mesma forma, nada, por si só, é igual ou diferente de qualquer outra coisa, ou seja, não existem equivalentes, mas somente translações;

- E, ainda, não existe nem todo nem parte. Nem existem harmonia, composição, integração ou sistema. O que há é um campo de batalha;

- Como consequência, por mais fracamente que um actante recruta outro, isso forma uma rede (network) que restringe a possibilidade de cada actante definir suas próprias associações. Desse modo, entre uma rede e outra, como entre uma força e outra, nada, por si só, é comensurável ou incomensurável. Não é possível se desvencilhar de uma rede - por mais que ela se estenda.

Em consequência, actantes só podem ser percebidos como complexos ou simples, somente se considerar as diversas associações por eles formadas. Essas associações, em consequência, são possibilitadas por translações sucessivas, como também já tinha mostrado Callon (1986), ao enfatizar que a sociologia deveria ser praticada por meio de uma "sociologia da translação".

Nos estudos organizacionais como um todo, a TAR surge como uma nova possibilidade de sair do "mundo único e mágico de estruturas e sistemas" como argumentou Andrade (2004, p. 11), ao buscar entender as organizações por uma perspectiva intermediária. Nesse sentido,

[...] ao invés de privilegiar macro ou microanálises, agência ou estrutura, humanos ou não humanos, a ideia é iniciar a análise sem noções pré-estabelecidas nos processos construtivos. A TAR pode contribuir com os estudos organizacionais, fundamentalmente, por não considerar organizações como entidades relativamente estáveis que possuem fronteiras claras, mas sim como o arranjo de redes heterogêneas que estão em constante processo de alteração, mudança e estabilização. Dessa forma, as organizações passam a ser vistas como resultados parciais que precisam ser explicados de maneira empírica, destacando que ao invés de estudar pessoas e estruturas sociais nas organizações, é fundamental compreendê-las como um conjunto de eventos e processos que não seguem, necessariamente, nenhuma lógica comum (ALCADIPANI e TURETA, 2009, p. 659).

Além disso, para Alcadipani e Tureta (2009, p. 659), "a [Teoria do Ator-Rede - TAR] oferece a possibilidade de analisar organizações como complexas e instáveis, sem assumir como certo a existência de fronteiras claras, permitindo focar no constante processo de organizar". Isso significa dizer, para esses autores, que para a TAR, estruturas organizacionais nunca são idênticas e cada uma é construída constantemente em contextos locais e específicos.

Desse modo, a TAR possibilita perceber que não existe um sistema macrossocial, por um lado, nem um conjunto de partes microssociais, por outro (LAW, 1992, p. 2), o que existe, de fato, são redes heterogêneas formadas por padrões diversos que envolvem simultaneamente sociedade, organizações, agentes e máquinas. Law (1992) chama atenção para o fato de que as organizações são processos estáveis unicamente momentâneos, sendo a TAR útil para perceber como padrões são gerados e como efeitos organizacionais ocorrem. A TAR, assim, possibilita que as organizações deixem de ser vistas como um conjunto de pessoas, tecnologias, normas, informações e outros elementos, materiais ou não, para mostrar que tudo não passa de uma rede, composta de narrativas, imersas em relações de envolvimento e interesse e que fazem com que perspectivas distintas se juntem para compor um entendimento único do que compõe uma organização. Estabelecer a priori, que é possível reduzi-la em diversas partes, ou em níveis de complexidade aparente, é pressupor que determinados fenômenos existem antes mesmo de ser estudados e descritos. Para a TAR, as organizações e tudo o que compõe o universo técnico, físico e social, nada mais são do que "redes de certos padrões de materiais heterogêneos" (LAW, 1992, p. 2). E essa heterogeneidade torna-se um conceito relevante na compreensão da TAR, já que toda rede é "esparsa, vazia, frágil e heterogênea" (LATOUR, 1988, p. 206). 
A heterogeneidade discutida na TAR, ao mesmo tempo que ela está interligada com a perspectiva contemporânea, por entender que o mundo material é igualmente fonte de agência, ela também está vinculada ao período renascentista, pois a heterogeneidade está na similitude entre olhar do sujeito que observa e as reações do objeto que, à sua maneira, "alicia" o sujeito. Mas a TAR se consolida também, e de fato, como oposição ao projeto clássico/moderno na medida em que recusa tratar sujeito e objeto como heterogeneidades distintas e sobrepostas. A TAR reduz ou amplia, dependendo do efeito observado, sujeito e objeto a meios heterogêneos indissociáveis, tornando-os como compósitos de um mesmo coletivo. Como efeito, surgem ordens que podem ser vistas (LAW, 1992), apesar dessas ordens serem mais provisórias do que a própria desordem inerente dessa relação sujeito/objeto (SERRES, 2000).

Desse modo, heterogeneidade para TAR, trata-se dos fluxos (LAW, 2011) dos coletivos e das maneiras como eles se comportam, estejam eles se apresentando simples, complexos, ordenados ou fluidos. O que importa é acompanhar os coletivos e suas associações. Coletivos são os agrupamentos, quase sempre provisórios, de quase objetos oriundos da indissociabilidade entre natureza, tecnologia e sociedade (LATOUR, 1994a). Quando os fluxos são passíveis de descrição se tem a translação. Quando eles se tornam estáticos e pontualizados (LAW, 1992), tem-se o ordenamento. Um exemplo prático, segundo Law (1992, p. 8), é olhar para as organizações:

[...] organização é uma conquista, um processo, uma consequência, um conjunto de resistências superadas, um efeito precário. Seus componentes - as hierarquias, os arranjos organizacionais, as relações de poder, e os fluxos hierarquias, os arranjos organizacionais, as relações de poder, e os fluxos de informação - são as consequências incertas da ordenação dos materiais heterogêneos.

A organização é o efeito da heterogeneidade, ou seja, de um fluxo de comportamento traduzido em "empreendimento", "gestão", "vocação", "visão", dentre outros, dos quais operam coletivamente para gerar agentes multiestratégicos (quase objetos), arranjos organizacionais (ordenamentos) e transações interorganizacionais (translações) (LAW, 1992). Simplificação ou complexidade representam, simplesmente, fases ou modos de ver e operar esses fluxos. A mediação é a unidade de análise para compreensão da heterogeneidade na TAR.

\section{MEDIAÇÃO COMO FOCO DE ANÁLISE DA HETEROGENEIDADE NA TEORIA ATOR-REDE}

O pressuposto, aqui, é que as interações dos actantes se dão de forma que eles nunca são causas completas das transformações ocorridas muito menos completas consequências (LATOUR, 2001). Citando a "pasteurização da França" (LATOUR, 1988), como exemplo, o próprio Louis Pasteur é transformado durante a passagem das completas gerações espontâneas de micróbios para a total existência do fermento (LATOUR, 2001). Tanto quanto Pasteur descobriu os micróbios, os micróbios também relevaram Pasteur. "Pasteur ajudou o fermento a mostrar quem era, o fermento 'ajudou' Pasteur a ganhar uma de suas muitas medalhas" (LATOUR, 2001, p. 145). Os diversos artigos que vieram a público sobre esse processo de pasteurização mediaram as diversas cadeias de translação que sedimentaram o processo de construção do fermento láctico. Desse modo, a mediação é o processo de evidenciação de relações de uma forma ou de outra (LAW, 2004), de modo que se torna possível acompanhar as transformações ocorridas pelas associações de actantes.

Para Latour (2001, p. 178), o olhar deve estar voltado à mediação ao considerar o social e o técnico de forma "que não seja nem uma causa completa nem uma completa consequência, nem inteiramente um meio nem inteiramente um fim". Ou seja, os eventos e actantes não podem ser determinados unicamente pelos seus fins, mas por meio de processos de translação ao possibilitar a criação de "um link que não existia antes, e que, em certa medida, modifica os dois elementos ou agentes [humano e não humano] envolvidos na relação" (LATOUR, 1994b, p. 32).

Nesse sentido, Latour (2001, p. 106-107) compreende que "a operação de translação consiste em combinar dois interesses até então diferentes [...] num único objetivo composto" à medida que "o que importa nessa operação de translação não é unicamente a fusão de interesses que ela enseja, mas a criação de uma nova mistura"; uma mistura sociotécnica. As questões sociais se transformam em questões técnicas e vice-versa, mobilizando agentes humanos e não humanos. Esse processo é permitido pelas mediações que culminam nas cadeias de translações "graças aos quais os atores [actantes] modificam, deslocam e transladam seus vários e contraditórios interesses" (LATOUR, 2001, p. 356). 
Para ilustrar essa discussão, vale a pena tomar como exemplo o caso da pedagogia da alternância, como discutido por Valadão (2014). Casos como esse têm sido cada vez mais relatados na literatura nacional e ilustram bem como lançar mão da TAR para análises empíricas a partir da concepção ontológica e epistemológica em que essa abordagem se baseia. A PA é um método pedagógico de formação básica para filhos de pequenos agricultores que surgiu na França, na década de 1930, para resolver a ausência de formação para os filhos dos agricultores. Por meio de um conjunto de instrumentos pedagógicos específicos, como Plano de Estudo (PE), Caderno da Realidade (CR) e Caderno da Alternância (CA), acompanhamento de aprendizagem personalizado chamado tutoria e um método de alternância que se baseia em aprendizagens formais tanto no período escolar como no período familiar. A PA tem sido documentada como um caso educacional de sucesso no mundo todo, inclusive no Brasil, com mais de 300 Centros Familiares de Formação por Alternância (CEFFA) em funcionamento na atualidade.

Seja o caso do professor que chega para trabalhar em um CEFFA. Ele sabe ensinar. Aprendeu métodos pedagógicos e já tem prática em aplicá-los no cotidiano do ensino. Por outro lado, o CEFFA possui a pedagogia da alternância, com instrumentos metodológicos específicos para a aprendizagem dos discentes. O CA, o CR, O PE, a tutoria, as visitas e as viagens de estudo, são alguns desses instrumentos.

Quem é responsável pela aprendizagem no CEFFA? A PA e seus instrumentos ou o professor que acabara de chegar? Se a PA não for aplicada não haverá resultados satisfatórios, alegará os responsáveis pelo CEFFA. Sem a minha performance não haverá aprendizagem, pode argumentar o professor. Uma encruzilhada com, pelo menos, três caminhos se apresenta. Em um primeiro caminho, o professor ensina e o CA é uma simples ferramenta para seu trabalho. Por outro, o professor agora, ao praticar o CA, torna-se um "instrumento" a serviço da aprendizagem dos jovens rurais. Em um terceiro caminho é possível perguntar, haverá um agente compósito chamado tutor, que articula os dois caminhos anteriores? A tutoria é o acompanhamento personalizado do professor junto ao discente que corrobora às suas atividades de ensino e de seu cotidiano escolar e familiar, subsidiada pelo CA que armazena os registros desse acompanhamento. Enquanto o paradigma da simplificação tentaria compreender cada um separadamente (PA, professor ou tutor), o paradigma da complexidade possivelmente tentaria compreender suas inter-relações ou o "sistema holístico" que eles formam.

O agente compósito, contudo, o tutor, tem um novo programa de ação a desenvolver. Programa de ação são as séries de objetivos, passos e intenções que podem ser descritos agora não mais a partir do professor ou do CA, mas do tutor (LATOUR, 2001). O tutor possibilita uma aprendizagem contextualizada à realidade do discente. Esse programa do tutor, todavia, é incerto quanto ao seu objetivo final. Os antiprogramas, ou seja, programas diferentes do ponto de vista do tutor, como o do CA, em priorizar as anotações cotidianas, ou do professor, em concentrar na reprodução dos conteúdos de ensino, pode tornar incerto os resultados de sua atuação. Essa incerteza é a translação de objetivos (LATOUR, 2001, p. 206), um dos significados de mediação proposto por Latour (2001), conforme mostrado na Figura 1.

Figura 1

Primeiro significado de mediação (translação de objetivos)

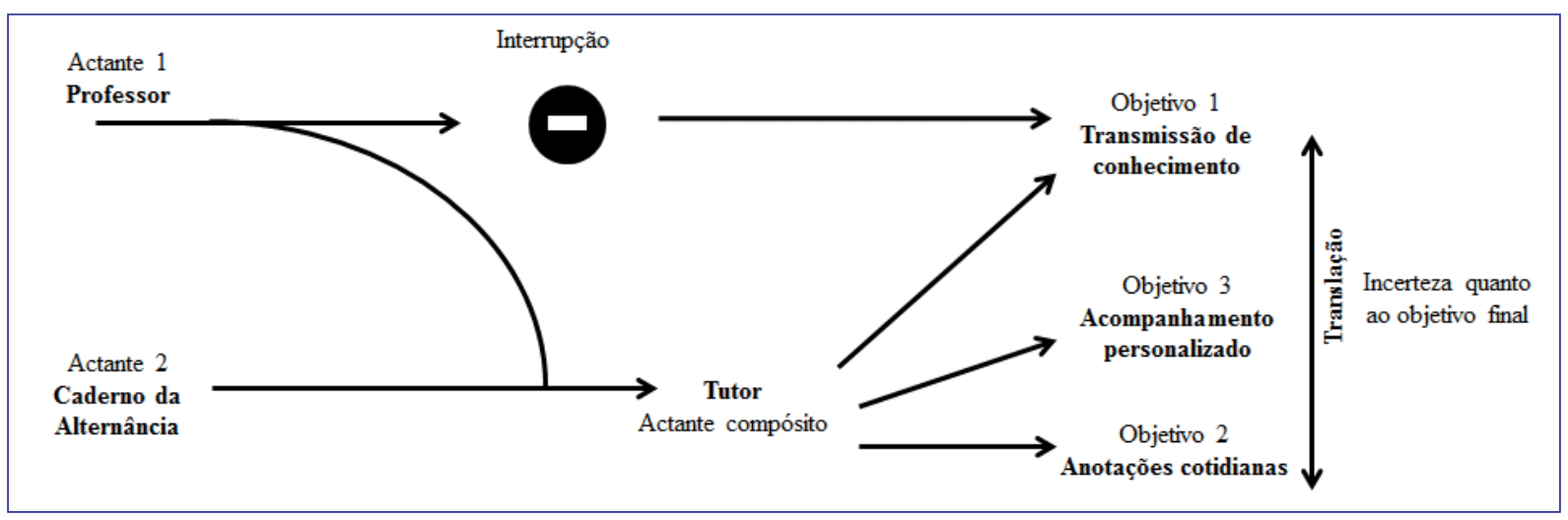

Fonte: Adaptada de Latour (2001). 
Com isso, ao considerar o professor e o CA como mediadores, percebe-se que "nem sujeito e nem objeto (e seus objetivos) são fixos". Quando esses mediadores são articulados eles se juntam "numa proposição nova. Tornam-se 'alguém, alguma coisa mais'" (LATOUR, 2001, p. 208). No caso, tem-se um ator híbrido chamado tutor.

Nessa história, contudo, é fácil supor que esse programa de ação não está sozinho. "Sem dúvida, em muitas histórias de ferramentas há não apenas um, mas dois ou mais subprogramas encaixados uns nos outros" (LATOUR, 2001, p. 208). A tutoria é somente um subprograma entre muitos outros dentro do CEFFA. De fato, para verificar isso basta considerar outro instrumento metodológico da PA, como é o caso do plano (PE). O PE é basicamente uma pesquisa elaborada periodicamente pelo professor e discentes, respondido no período familiar pelos familiares dos jovens e sistematizada no período escolar. Seu objetivo é integrar família e escola. O CR armazena tudo o que acontece nessa realização do PE. Ele é um ator que permite visibilidade ao subprograma PE (VALADÃO, 2014).

O professor agora precisa continuar integrado ao CA para desenvolver a tutoria, mas precisa estar vinculado também ao CR para realizar o PE. Ele e o CA não são autônomos. Eles precisam da participação da família. E quem assegura essa participação é o PE. Em consequência, se ao professor não é mais permitido somente transmitir conhecimentos, a via do CA para exercer a tutoria também é interrompida e passa a ser condição incluir o CR em seu trajeto. Tem-se assim uma composição de actantes. Outro significado de mediação proposto por Latour (2001), conforme pode ser visto na Figura 2.

Figura 2

\section{Segundo significado de mediação (composição)}

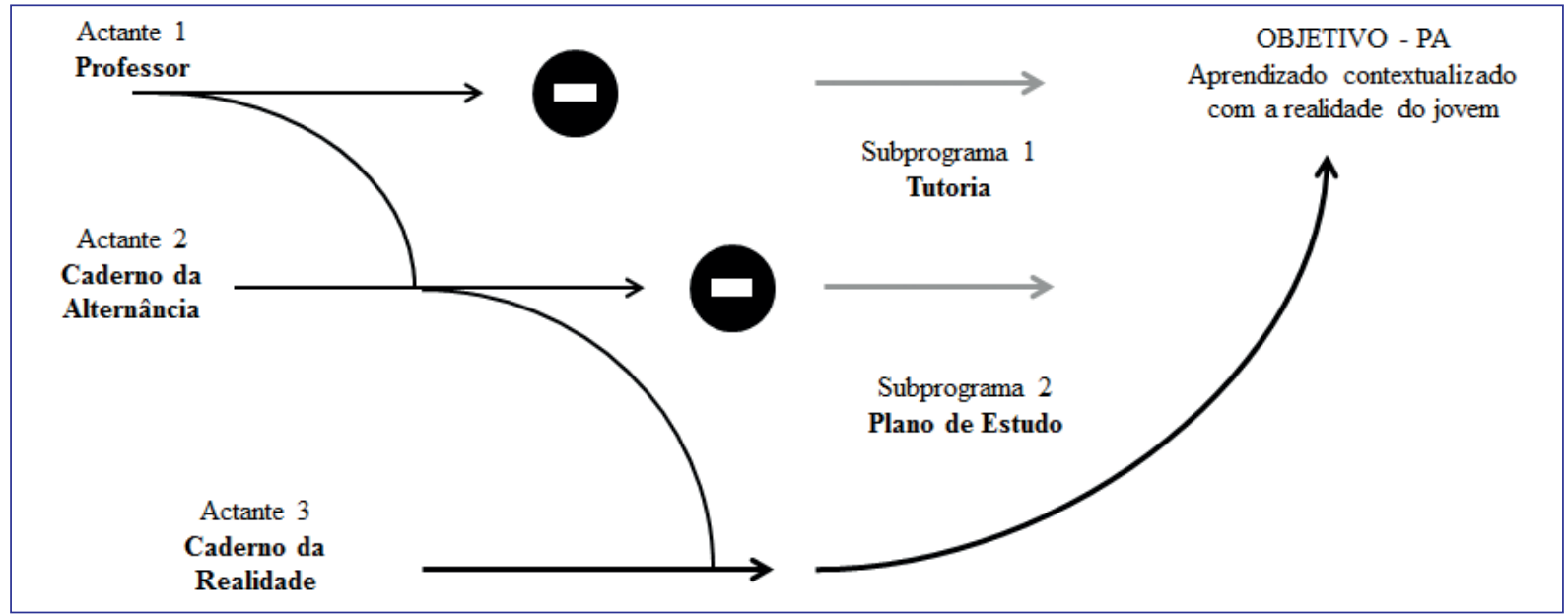

Fonte: Adaptada de Latour (2001).

Como visto, "quando o número de subprogramas aumenta, o objetivo composto - aqui, a linha curva fina - torna-se a realização comum de cada um dos agentes [actantes] curvados pelo processo de translação sucessiva" (LATOUR, 2001, p. 209). A ação da PA, na junção desses subprogramas, torna-se mais acentuada. Isso, pois, "a ação não é uma propriedade de humanos, mas de uma associação de atuantes [actantes]" (LATOUR, 2001, p. 2010, grifo do autor).

E o que pode acontecer com o professor ao longo de todo esse processo? Naturalmente ele pode ir se deslocando nas diversas associações que for compondo dentro do CEFFA. A cada novo subprograma que o professor se envolver, um entrelaçamento natural de tempo e espaço pode ocorrer. Isso pode chegar ao ponto de sua participação tornar-se obscura ao longo do tempo. $O$ "obscurecimento" é um processo em que os actantes estão sujeitos e que "torna a produção conjunta de atores e artefatos inteiramente opaca" (LATOUR, 2001, p. 210-211). O obscurecimento se dá na medida em que o professor, ao invés de desinteressar pela PA e continuar seu caminho no ensino tradicional, se integra cada vez mais intensamente com cada programa e subprograma da PA.

O processo de "obscurecimento", para Latour (2001), desenrola-se deste um passo inicial de total desinteresse, aqui no caso do professor pela PA, mas que até certo ponto também não deixa de ser da PA pelo professor, até um passo último de pontualização, em que o professor deixa de ser percebido como professor e passar a ser parte do "compósito PA". Para Latour 
(2001, p. 212) o processo também pode ser inverso, "qualquer conjunto de artefatos pode ser movido para cima ou para baixo nessa sucessão de passos, dependendo da crise que sofra". Esse movimento de "obscurecimento reversível", que pode ir do desinteresse à pontualização ou vice-versa, como pode ser visto na Figura 3. Latour (2001) designou como sendo o terceiro significado de mediação.

Figura 3

Terceiro significado de mediação (obscurecimento reversível)

\begin{tabular}{|c|c|}
\hline $\begin{array}{l}\mathrm{AO} \longrightarrow \\
\mathrm{BO} \longrightarrow\end{array}$ & Passo 1: Desinteresse \\
\hline $\begin{array}{ll}\mathrm{A} & 0 \\
\mathrm{~B} & 0\end{array}$ & $\begin{array}{l}\text { Passo 2: Interesse } \\
\text { (interrupção, desvio, } \\
\text { aliciamento) }\end{array}$ \\
\hline$\underset{\mathrm{CO}}{\mathrm{AO}}$ & $\begin{array}{c}\text { Passo 3: Composição de um } \\
\text { novo objetivo }\end{array}$ \\
\hline $\mathrm{A}_{\mathrm{B}}^{\mathrm{O}}$ & $\begin{array}{c}\text { Passo 4: Ponto de passagem } \\
\text { obrigatório }\end{array}$ \\
\hline $\begin{array}{ccc}A & B & C \\
0 & -0 & 0\end{array}$ & Passo 5: Alinhamento \\
\hline & Passo 6: Obscurecimento \\
\hline $\mathrm{DO}^{-}$ & Passo 7: Pontualização \\
\hline
\end{tabular}

\begin{tabular}{|c|c|}
\hline $\begin{array}{c}\text { O professor não conhece a PA ou não que } \\
\text { trabalhar no CEFFA. }\end{array}$ \\
$\begin{array}{c}\text { O professor deixa seu trabalho e é } \\
\text { aliciado, desviado, para o trabalho com a } \\
\text { PA. }\end{array}$ \\
$\begin{array}{c}\text { O professor torna-se tutor. Participante do } \\
\text { PA; acompanhante do CR etc. }\end{array}$ \\
$\begin{array}{c}\text { As funções para o professor-tutor } \\
\text { começam a ter definições claras. Ele } \\
\text { agora é monitor. }\end{array}$ \\
\hline $\begin{array}{c}\text { O monitor é totalmente familiarizado com } \\
\text { a PA. Ele começa a ser visto como parte } \\
\text { da PA }\end{array}$ \\
$\begin{array}{c}\text { Na composição da PA está o monitor. Ele } \\
\text { não pode ser visto fora dela. }\end{array}$ \\
$\begin{array}{c}\text { O monitor deixa de ser visto dentro da } \\
\text { PA. Ele é só mais um actante. A PA viaja } \\
\text { desinteressada, como diria Latour. }\end{array}$ \\
\hline
\end{tabular}

Fonte: Adaptada de Latour (2001).

Nota-se que quem ou o que foi pontualizado nos passos finais do processo de obscurecimento não foi mais o professor. O que aconteceu com ele nesse entrelaçamento de tempo e espaço? Inicialmente seus objetivos foram visivelmente transladados. Ao invés de livros didáticos, aulas expositivas e conteúdos tradicionais, ele e cada vez menos ele, foi sendo envolvido com tutoria, PE, CR dentre outros instrumentos que divergem consideravelmente de suas relações até então habituais. Pode-se dizer que há um visível desvio na atuação do professor. Mas não só, "a noção de desvio, de translação deve ser modificada para absorver não apenas [...] uma nova definição de objetivos e funções, mas também uma alteração na própria substância expressiva" (LATOUR, 2001, p. 214, grifo do autor). A translação não mais significa, nessa situação, o desempenho de novas e diferentes atividades e funções. Ele agora ganha novas dimensões. A translação encarrega de fazer desaparecer o professor. Seu significado muda. Ele é incorporado na PA de forma que sua identidade torna-se outra, no caso, emerge a figura do actante monitor.

Em conceituação simples, "os monitores formam um componente essencial do sistema de formação alternada. É sobre eles que se apoia, no dia a dia, o funcionamento pedagógico, educativo e material do CEFFA" (GIMONET, 2007, p. 145). O monitor está inter-relacionado integralmente com a PA. Ele é parte dela. Está totalmente articulado na PA. Ou poderia ser também “objetificado, reificado, realizado, materializado ou gravado" (LATOUR, 2001, p. 214). O que deve ser considerado é evitar a ideia de que esses termos "implicam um agente humano todo-poderoso impondo sua vontade à matéria informe", pois os não humanos presentes na PA, como visto, também "agem, deslocam objetivos" e contribuem na definição (LATOUR, 2001) do monitor. O monitor ajuda na realização da PA e a PA dá vida ao monitor. 
Desse modo, tem-se aqui outro processo de translação, diferente do primeiro caso, em que foi considerado translação a interferência do professor na aplicação da PA. "Aqui, porém, a mudança de significado é muito maior, pois a própria natureza do 'significado' foi alterada. A substância da expressão modificou-se ao longo do caminho" (LATOUR, 2001, p. 215). Essa mudança de significado Latour (2001) denominou delegação, como mostra a Figura 4.

Figura 4

\section{Quarto significado de mediação (delegação)}

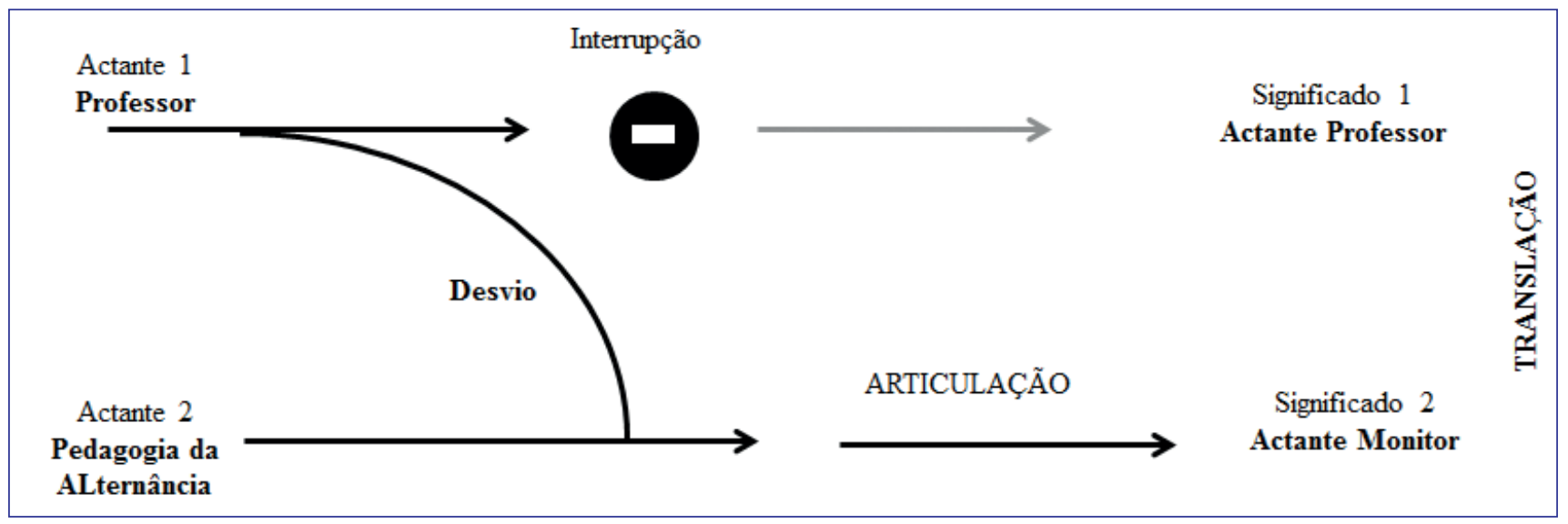

Fonte: Adaptada de Latour (2001).

A translação por delegação não é um simples deslocar de actantes. "Não apenas o transporto para outro espaço e tempo como o transformo em outro ator. [...]. A finalidade do deslocamento é espacial, temporal e 'atorial'” (LATOUR, 2001, p. 216). O deslocamento do professor é espacial, pois ele não mais está na escola pública ou na escola privada, ele agora está no CEFFA. É temporal, pois dia e noite agora está envolvido com a PA e não mais com o ensino tradicional. E é atorial, pois ele agora é um monitor e não dá pra ser confundido com um professor.

Assim, a mediação "reside no ponto cego onde sociedade e matéria trocam propriedades" (LATOUR, 2001, p. 218). O professor deixou de ser professor e, possivelmente, os instrumentos metodológicos não são mais os mesmos depois de sua presença. Da mesma forma, "os mediadores têm a capacidade de traduzir aquilo que eles transportam, de redefini-lo, desdobrá-lo, e também traí-lo" (LATOUR, 1994a, p. 80). Isso é visível ao olhar para o próprio monitor. Seu futuro parece mais dependente da PA do que a PA dele, apesar dessa relação ser totalmente simétrica. Em consequência o próprio conceito de translação acaba definido. A translação é o deslocar dos actantes nesses processos mediativos. Para Callon (1986), a translação enfatiza a continuidade, os deslocamentos e as transformações que ocorrem nas muitas fases da história dos actantes e em suas atuações como mediadores. O desafio de qualquer esforço para entender as complexidades de eventos como a PA consiste em acompanhar esse deslocamento.

O problema, aqui, é assumir a concretude do monitor, como pressuposto nos paradigmas da complexidade e simplificação, e tentar compreender a realidade a partir dela, esquecendo que essa concretude nada mais é do que o resultado da "expressiva substância", formada pela interação de um conjunto de actantes que permitem visualizar a PA como uma forma pedagógica concreta. Na perspectiva da TAR, a heterogeneidade é o compósito em termos de escala, tempo, espaço, performance e todas as heterotopias possíveis que compõem e definem a realidade por meio dessa "expressiva substância" que transladam cotidianamente.

\section{CONCLUSÃO}

Esse artigo procurou discutir e refletir sobre a relevância de considerar nos estudos organizacionais a heterogeneidade que atualmente perfaz as organizações. Sete pontos, basicamente, foram discutidos. Uma reflexão inicial, que corrobora aos diversos estudos contemporâneos que criticam o paradigma simplificador moderno e toda sua concepção epistemológica de ciência. Posteriormente, foram apresentados o paradigma da complexidade e o avanço ocorrido a partir de então, se comparado à concepção científica hegemônica da modernidade e suas implicações para os estudos organizacionais. Em seguida, foi 
apresentada a trajetória histórica da heterogeneidade, a adequação da base epistemológica da TAR para tratá-la nos estudos organizacionais, e a mediação como foco de análise da heterogeneidade na TAR.

De modo geral, a TAR tem-se tornado, cada vez mais, uma lente de análise relevante para compreensão dos fenômenos organizacionais. Além da compreensão das subjetividades inerentes às organizações, a heterogeneidade permite compreender como essas subjetividades se materializam de modos objetivos e concretos, pois a TAR permite compreender as redes de atores performadas, ordenadas, específicas, múltiplas e todas as suas heterogêneas formas e características. Pressupor um paradigma da complexidade exige, em contrapartida, novas formas epistemológicas, como possibilitado pela TAR, para entender as múltiplas realidades que compõem o cotidiano das pesquisas em Administração.

A vantagem de trabalhar na perspectiva da heterogeneidade relacional discutida neste artigo destaca-se, sobretudo, pela possibilidade de considerar a simetria e a agnosticidade nas análises e pressupor a livre associação dos atores-redes. Uma postura agnóstica contribui para a compreensão das heterogeneidades relacionais, pois permite que todas as entidades humanas e não humanas e explicações racionais ou místicas possam ser levadas em consideração na análise, sem que nenhum ponto de vista seja privilegiado e nenhuma interpretação seja censurada. Além disso, permite que o pesquisador abandone todas as distinções, a priori, entre eventos naturais e sociais. O pesquisador, de maneira agnóstica, pode seguir os atores e identificar a maneira como eles definem e associam os diferentes elementos, por meio dos quais constroem e explicam seus mundos (CALLON, 1986). Ao analisar a realidade de maneira simétrica, como pressupõe na TAR, os deslocamentos e as transformações decorrentes das associações são descritos a partir dos mesmos termos usados para todos os atores da rede. $\mathrm{O}$ social passa a ser descrito a partir dos próprios atores e não uma entidade dada a priori, como se pressupõe tanto na simplificação como na complexidade.

Para aprofundamento e novos estudos, o leitor não pode deixar de ler pesquisas que corroboram as afirmações deste artigo. O leitor pode optar por trabalhos mais clássicos, que discutem, sobretudo, a concepção da TAR, como é o caso da "navegação portuguesa" desenvolvido por Law (1986), a "pasteurização da França" desenvolvido por Latour (1988) e a "domesticação das vieiras e os pescadores da Baía de StBrieuc" de Callon (1986). Ou trabalhos mais voltados à definição ou caracterização do conceito de heterogeneidade, como é o caso da descrição da "hipoglicemia" (LAW e MOL, 2004), da "febre aftosa" (LAW e SINGLETON, 2014) e do "desastre nuclear de Fukushima" (LAW, 2011). Além, é claro, de acompanhar as pesquisas que vêm sendo desenvolvidas no Brasil, como é o caso da "erradicação do trabalho infantil no Brasil" de Andrade (2004), a "formação do campo da biotecnologia" de Andrade (2011), o "complexo público de pesquisa" de Tonelli (2011), a "evolução da Escola de Samba", como relatado por Tureta (2011), as "associações sociotécnicas e as práticas de gestão do P1MC" de Andrade, Cordeiro Neto e Valadão (2013) e a "translação da Pedagogia da Alternância" descrita por Valadão (2014), dentre outras.

Para a realização desses estudos, contudo, é preciso realizar esforços metodologicamente, no sentido de identificar quais evidências de associação ocorrem entre esses actantes ou, como disse Latour (2000), como são disputados os "inter-esse" (interesse), isto é, "aquilo que está entre os atores e seus objetivos" (LATOUR, 2000, p. 179), fazendo-os escolher uma, ou algumas, dentre muitas possibilidades. $\mathrm{O}$ segundo esforço consiste em identificar e acompanhar as fases das performances dos actantes a partir das possibilidades escolhidas ou, como mostrou Callon (1986), como os atores se tornam indispensáveis (mobilização), quais ações e dispositivos são usados para assegurar a participação dos demais (interessamento), como as funções são definidas e coordenadas (inscrição) e que porta-vozes resultaram da associação estabilizada (mobilização). E, por fim, procurar sempre evidenciar quais controvérsias (acordos, dissidências, traições) resultaram das articulações dos interesses (primeiro esforço) e dos descolamentos ocorridos (segundo esforço). O trabalho de Callon (1986) contribui, significativamente, para uma realização metodológica coerente com os fundamentos ontológicos e epistemológicos discutidos neste artigo.

Para o futuro das pesquisas no país, sugere-se, a partir desta discussão, a realização de estudos teóricos mais aprofundados para melhor compreensão da inter-relação das bases que sustentam tanto o paradigma da complexidade, proposto por Morin, como a concepção sociológica e antropológica proposta por Callon, Law e Latour. Enquanto os estudos empíricos têm avançado consideravelmente na aplicação dos conceitos da TAR, muito ainda falta para uma melhor compreensão de suas implicações epistemológicas nos estudos organizacionais como um todo. É relevante no contexto brasileiro, principalmente no contexto da administração pública, estudos que vão, como disse Corrêa (2014), "do problema do social ao social como problema". Nesse sentido, uma agenda de pesquisa poderia ser desenvolvida envolvendo não só a TAR, mas toda a sociologia pragmática francesa. Um conjunto de trabalhos poderia ser elaborado baseando-se na TAR, nos regimes de justificação de Luc Boltanski e Laurent Thévenot, nos tempos de crises, como discutido por Francis Chateauraynaud, dentre outros, como já sinalizam alguns grupos e trabalhos no Brasil - por exemplo, os trabalhos de Krieger (2011) e Karam (2014). 


\section{REFERÊNCIAS}

ALCADIPANI, R.; TURETA, C. Teoria Ator-Rede e estudos críticos em administração: possibilidades de um diálogo. Cadernos EBAPE.BR, v. 7, n. 3, p. 406-418, 2009.

ANDRADE, É. Uma crítica à teoria da complexidade proposta por Edgar Morin. Dissertatio, v. 26, p. 167-187, 2007.

ANDRADE, J. A. O espaço público como uma rede de atores: a formação da política de erradicação do trabalho infantil no Brasil. 219 f. Tese (Doutorado em Administração) - Programa de PósGraduação em Administração, Universidade Federal do Rio Grande do Sul, Porto Alegre, 2004

ANDRADE, J. A. Organon e as redes: uma reflexão sobre produções sociotécnicas. Revista Gestão e Sociedade, v. 4, n. 7, p. 435-457, 2010.

ANDRADE, J. A. What holds us together? Analyzing biotech field formation. Journal of Technology Management \& Innovation, v. 6, n. 3, p. 1-12, 2011.

ANDRADE, J. A.; CORDEIRO NETO, J. R.; VALADÃO, J. A. D. Associações sociotécnicas e práticas de gestão em desenvolvimento: analisando rastros por entre o traçado do P1MC. Cadernos EBAPE.BR, v. 11, n. 2, p. 274-294, 2013.

BERTALANFFY, L. V. Teoria geral de sistemas. Petropólis, RJ: Vozes, 1977.

BERTERO, C. O. Produção científica em administração de empresas: provocações, insinuações e contribuições para um debate. Revista de Administração Contemporânea, v. 3, n. 1, p. 147-178, 1999.

BLOOR, D. Conhecimento e imaginário social. 2. ed. São Paulo: Ed. Unesp, 2009.

BOEIRA, S. L.; VIEIRA, P. F. Estudos organizacionais: dilemas paradigmáticos e abertura interdisciplinar. In: SILVA, A. B.; GODOI, C. K.; BANDEIRA-DE-MELO, R. (Org.). Pesquisa qualitativa em estudos organizacionais: paradigmas, estratégias e métodos. 2. ed. São Paulo, 2010. p. 17-52.

BURRELL, G.; MORGAN, G. Sociological paradigms and organisational analysis: elements of the sociology of corporate life. London: Heinemann, 1979.

BURRELL, G. Ciência normal, paradigmas, metáforas, discursos e genealogia da análise. In: CLEGG, S. R.; HARDY, C.; NORD, W. R. Handbook de estudos organizacionais: modelos de análise e novas questões em estudos organizacionais. São Paulo: Atlas, 2010. v. 1, p. $437-460$

CALLON, M. Some elements of a sociology of translation: domestication of the scallops and the fishermen of St. Brieuc Bay. In: LAW, J. Power, action and belief: a new sociology of knowledge? London: Routledge, 1986. p. 196-223

CALLON, M. Society in the making: the study of technology as a tool for sociological analysis. In: BIJKER. W. E; HUGUES, T. P.; PINCH, T. J. (Eds.). The social construction of technological systems: new directions in the sociology and history of technology. Cambridge: The MIT Press, 1987, pp.83-103.

CALLON, M. El proceso de construcción de la sociedad. El studio de la tecnología como herramienta para el análisis sociológico. In DORMÈNECH, M.; TIRADO, F. J. Sociología simétrica: ensayos sobre ciencia, tecnología y sociedad. Barcelona: Gedisa, 1998. p. 143-170.
CALLON, M. Actor-network theory: the market test. In: LAW, J.; HASSARD, J. (Org.). Actor-Network Theory and after. London: Blackwell, 1999. p. 181-195.

CAPRA, F. A teia da vida: uma nova compreensão científica dos sistemas vivos. São Paulo: Cultrix, 1996.

CAPRA, F. Ponto de mutação. São Paulo: Cultrix, 2006.

CORRÊA, D. S. Do problema do social ao social como problema: elementos para uma leitura da sociologia pragmática francesa. Política \& Trabalho, n. 40, 2014. pp. 35-62.

DAGNINO, R.; BRANDÃO, F. C.; NOVAES, H. T. Sobre o marco analíticoconceitual da tecnologia social. In: DAGNINO, R. (Org.). Tecnologia social: ferramenta para construir outra sociedade. 2. ed. Campinas, SP: Komedi, 2010. p. 71-112.

DESCARTES, R. Discurso sobre o método. In: DESCARTES. São Paulo: Abril Cultural, 1980. (Coleção Os Pensadores).

GIMONET, J. C. Praticar e compreender a pedagogia da alternância dos CEFFAs. Petropolis, RJ: Vozes, 2007

GODOI, C. K.; BANDEIRA-DE-MELO, R.; SILVA, A. B.. Pesquisa qualitativa e o debate sobre a propriedade de pesquisar. In: SILVA, A. B.; GODOI, C. K.; BANDEIRA-DEMELO, R. (Org.). Pesquisa qualitativa em estudos organizacionais: paradigmas, estratégias e métodos. 2. ed. São Paulo, 2010. p. 1-15.

GUERREIRO RAMOS, A. A nova ciência das organizações: uma reconceituação da riqueza das nações. Rio de Janeiro: Ed. FGV, 1981.

HETHERINGTON, K. From blindness to blindness: museums, heterogeneity and the subject. In: HASSARD, J. (Ed.). Actor-Network Theory and after. The sociological review. Oxford: Blackwell, 1999. p. 51-73.

KARAM, C. Legitimando uma inovação social: o caso do corpo de bombeiros voluntários de Joinville. $404 \mathrm{f}$. Tese (Doutorado em Administração) - Universidade Federal de Santa Cantarina, Florianópolis, 2014

KRIEGER, M. Legitimidade das organizações da sociedade civil na região Sul do Brasil: uma análise da percepção dos atores do campo à luz da sociologia pragmática. 254 f. Dissertação (Mestrado em Administração) - Centro de Ciências da Administração e Socioeconômicas, Universidade do Estado de Santa Catarina, Florianópolis, 2011.

LATOUR, B. The pasteurization of France. Cambridge, MA: Harvard University Press, 1988.

LATOUR, B. "Where are the missing masses? The sociology of a few mundane artifacts." In: BIJKER, W. E.; PINCH, T. F.; LAW, L. (Ed.). Shaping technology/building society: studies in sociotechnical change. Cambridge, MA: The MIT Press, 1992. p. 225-258.

LATOUR, B. Jamais fomos modernos: ensaio de antropologia simétrica. Rio de Janeiro: Ed. 34, 1994a.

LATOUR, B. On technical mediation: philosophy, sociology, genealogy. Common Knowledge, v, 3, n. 2, p. 29-64, 1994b.

LATOUR, B. La tecnología es la sociedad hecha para que dure. In: DORMÈNECH, M.; TIRADO, F. J. Sociología simétrica: ensayos sobre ciencia, tecnología y sociedad. Barcelona: Gedisa, 1998. p. 109-142. 
LATOUR, B. On recalling ANT. In: LAW, J.; HASSARD, J. (Ed.). ActorNetwork Theory and after. The Sociological Review. Oxford: Blackwell Publishers, 1999. p. 15-25.

LATOUR, B. Ciência em ação: como seguir cientistas e engenheiros sociedade afora. São Paulo: Ed. Unesp, 2000.

LATOUR, B. A esperança de Pandora: ensaios sobre a realidade dos estudos científicos. Bauru, SP: Edusc, 2001.

LATOUR, B. Políticas da natureza: como fazer ciência na democracia. São Paulo: Bauru, SP: Edusc, 2004.

LATOUR, B. Reagregando o social: uma introdução à teoria do AtorRede. Salvador: Ed. UFBA, 2012.

LAW, J. On the methods of long-distance control: vessel, navigation and the Portuguese route to India. In: LAW, J. Power action and believe: a new sociology of knowledge? Heley: Routledge, 1986. p. 234-263.

LAW, J. Notes on the theory of the actor network: ordering, strategy and heterogeneity. Systemic Practice and Action Research, v. 5 , n. 4, 1992. pp. 379-393.

LAW, J. Del poder y suas tácticas: un enfoque desde la sociología de la ciencia. In: DORMÈNECH, M.; TIRADO, F. J. Sociología simétrica: ensayos sobre ciencia, tecnología y sociedad. Barcelona: Gedisa, 1998. p. 63-108.

LAW, J. After ANT: complexity, naming and topology.In: LAW, J.; HASSARD, J. (Org.). Actor-Network Theory and after. London: Blackwell, 1999. p. 1-14.

LAW, J. After method: mess in social science research. New York: Routledge, 2004.

LAW, J. Actor-Network Theory and material semiotics. Lancaster: Lancaster University, 2007.

LAW, J. Heterogeneous engineering and tinkering. 2011. Disponível em: <http://www.heterogeneities.net/publications/ Law2011HeterogeneousEngineeringAndTinkering.pdf $>$. Acesso em: 24 maio 2012.

LAW, J.; MOL, A. Embodied action, enacted bodies: the example of hypoglycaemia. Body \& Society, v. 10, n. 2-3, p. 43-62, 2004.

LAW, J.; SINGLETON, V. Performing technology's stories: on social constructivism, performance, and performativity. Technology and Culture, v. 41, n. 4, p. 765-775, 2000.

LAW, J.; SINGLETON, V. ANT, multiplicity and policy. 2014 Disponível em: <http://www.heterogeneities.net/publications/ LawSingleton2014ANTMultiplicityPolicy.pdf>. Acesso em: 30 nov. 2017.

LEÃO, A. L. M. S.; MELLO, S. C. B.; VIEIRA, R. S. G. O papel da teoria no método de pesquisa em administração. Organizações em Contexto, v. 5 , n. 10,2009 . pp. 1-16.

LE MOIGNE, J. L. A teoria do sistema geral: teoria da modelização. Lisboa: Instituto Piaget, 1977.

MARSDEN, R.; TOWNLEY, B. The owl of Minerva: reflections on theory in practice. In: CLEGG, S.; HARDY, C. (Ed.). Studying organization: theory \& method. London: SAGE, 1999. p. 405-422.

MISOCZKY, M. C. A. Da abordagem de sistemas abertos à complexidade: algumas reflexões sobre seus limites para compreender processos de interação social. Cadernos EBAPE.BR, v. 1, n. 1, p. 01 -17, 2003.

MOL, A. The body multiple: ontology in medical practice. London: Duke University Press, 2002.
MORGAN, G. Paradigmas, metáforas y resolución de problemas en teoría de la organización. Ithaca, NY: Cornell University, 1980.

MORGAN, G. Imagens da organização. São Paulo: Atlas, 2002.

MORGAN, G. Paradigmas, metáforas e resolução de quebra-cabeças na teoria das organizações. Revista de Administração de Empresas, v. 45. n. 1, p. 58-71, 2005.

MORIN, E. Ciência com consciência. Rio de Janeiro: Bertrand, 2000.

MORIN, E. A organização (do objeto ao sistema). In: MORIN, E. O método: a natureza da natureza. 2. ed. Porto Alegre: Sulina, 2005. v. 1.

MORIN, E. Ciência com consciência. 11. ed. Rio de Janeiro: Bertrand Brasil, 2008.

MORIN, E.; LE MOIGNE, J. A inteligência da complexidade. São Paulo: Peirópolis, 2000.

PETRAGLIA, I. C. Edgar Morin: a educação e a complexidade do ser e do saber. 7. ed. Petrópolis, RJ: Vozes, 2002

PLASTINO, C. A. O primado da afetividade: a crítica freudiana ao paradigma moderno. Rio de Janeiro: Relume-Dumará, 2001.

SANTOS, B. S. A crítica da razão indolente: contra o desperdício da experiência. São Paulo: Cortez, 2000.

SERRES, M. The bird of physics. Manchester: Clinamen Press, 2000.

SERVA, M. O paradigma da complexidade e a análise organizacional. Revista de Administração de Empresas, v. 32, n. 2, p. 26-35, 1992.

SERVA. M.; DIAS, T.; ALPERSREDT, G. D. Paradigma da complexidade e as teorias das organizações. Revista de Administração de Empresas, v. 50, n. 3, p. 276-287, 2010.

SHAPIRO, S. Agency theory. Annual Review of Sociology, v. 31, p. 263-284, 2005.

SILVA, A. B.; ROMAN NETO, J. Perspectiva multiparadigmática nos estudos organizacionais. In: SILVA, A. B.; GODOI, C. K.; BANDEIRA-DE-MELO, R. (Org.). Pesquisa qualitativa em estudos organizacionais: paradigmas, estratégias e métodos. 2. ed. São Paulo, 2010. p. 5387.

THOMPSON, G. F. Between hierarchies and markets: the logic and limits of network forms of organization. Oxford: Oxford University Press, 2003.

TONELLI, D. F. O empreendedorismo de base tecnológica no complexo público de pesquisa em Minas Gerais: um olhar pelo calidoscópio da Teoria do Ator-Rede. 288 f. Tese (Doutorado em Administração) - Programa de Pós-Graduação em Administração, Universidade Federal de Lavras, Lavras, 2011.

TURETA, C. Práticas organizativas em escolas de samba: o setor de Harmonia na produção do desfile do Vai-Vai. 325 f. Tese (Doutorado em Administração de Empresas) - Fundação Getulio Vargas, São Paulo, 2011.

VALADÃO, J. A. D. Seguindo associações sociotécnicas sob a luz da teoria do ator-rede: uma tradução da pedagogia da alternância para rotinas e tecnologias sociais. $294 \mathrm{f}$. Tese (Doutorado em Administração) - Programa de Pós-Graduação em Administração, Universidade Federal de Pernambuco, Recife, 2014.

WINNER, L. The whale and the reactor: a search for limits in an age of high technology. Chicago, IL: University of Chicago Press, 1986. 
Doutora em Administração pela Universidade Federal de Pernambuco (PROPAD/UFPE); Professora Adjunta na Universidade Federal de Campina Grande (UFCG), Campina Grande - PB, Brasil. E-mail: veronicamacario@gmail.com

José de Arimatéia Dias Valadão

Doutor em Administração pela Universidade Federal de Pernambuco (PROPAD/UFPE); Professor Adjunto no Curso Bacharelado em Administração Pública e Coordenador do Programa de Pós-Graduação em Administração Pública da Universidade Federal de Lavras (UFLA), Lavras - MG, Brasil. E-mail: arimateiavaladao@hotmail.com 